\title{
EphB2 in the Medial Prefrontal Cortex Regulates Vulnerability to Stress
}

\author{
Ruo-Xi Zhang ${ }^{1,2,3,5}$, Ying Han ${ }^{1,2,3,5}$, Chen Chen ${ }^{1,5}$, Ling-Zhi $\mathrm{Xu}^{2,3}$, Jia-Li Li ${ }^{2}, \mathrm{Na} \mathrm{Chen}^{2}$, Cheng-Yu Sun ${ }^{1,2}$, \\ Wen-Hao Chen', Wei-Li Zhu ${ }^{2}$, Jie Shi ${ }^{2}$ and Lin Lu*,1,2,4 \\ I'Institute of Mental Health, National Clinical Research Center for Mental Disorders, Key Laboratory of Mental Health and Peking University Sixth \\ Hospital, Peking University, Beijing, China; ${ }^{2}$ National Institute on Drug Dependence and Beijing Key Laboratory of Drug Dependence, Peking \\ University, Beijing, China; ${ }^{3}$ Department of Pharmacology, School of Basic Medical Sciences, Peking University Health Science Center, Beijing, China; \\ ${ }^{4}$ Peking-Tsinghua Center for Life Sciences and PKU-IDG/McGovern Institute for Brain Research, Peking University, Beijing, China
}

\begin{abstract}
The ephrin B2 (EphB2) receptor is a tyrosine kinase receptor that is associated with synaptic development and maturation. It has recently been implicated in cognitive deficits and anxiety. However, still unknown is the involvement of EphB2 in the vulnerability to stress. In the present study, we observed decreases in EphB2 levels and their downstream molecules in the medial prefrontal cortex (mPFC) but not in the orbitofrontal cortex (OFC) in mice that were susceptible to chronic social defeat stress. The activation of EphB2 receptors with EphrinBI-Fc in the mPFC produced stress-resistant and antidepressant-like behavioral effects in susceptible mice that lasted for at least 10 days. EphB2 receptor knockdown by short-hairpin RNA in the mPFC increased the susceptibility to stress and induced depressive-like behaviors in a subthreshold chronic social defeat stress paradigm. These behavioral effects were associated with changes in the phosphorylation of cofilin and membrane $\alpha$-amino-3-hydroxy-5-methyl-4-isoxazolepropionic acid receptor (AMPAR) trafficking and the expression of some synaptic proteins in the mPFC. We also found that EphB2 regulated stress-induced spine remodeling in the mPFC. Altogether, these results indicate that EphB2 is a critical regulator of stress vulnerability and might be a potential target for the treatment of depression.

Neuropsychopharmacology (2016) 4I, 254I-2556; doi:I0.I038/npp.20 I6.58; published online II May 2016
\end{abstract}

\section{INTRODUCTION}

Major depressive disorder (MDD) is a widespread psychiatric disorder that greatly influences public health (Krishnan and Nestler, 2008). Both genetic and environmental factors, such as stress, are involved in the etiology of depression (Kendler et al, 1999). However, only a small percentage of individuals, both humans and rodents, develop mental illnesses (eg, posttraumatic stress disorder and depression) when exposed to extraordinary levels of stress and trauma (Golden et al, 2011; Krishnan et al, 2007; Yu et al, 2012). Individuals who have the ability to perceive adversity as minimally threatening and consequently develop adaptive physiological and psychological responses to avoid negative social, psychological, and biological consequences of stressful events are identified as resilient (Russo et al, 2012). A better understanding of the neural and molecular mechanisms that

\footnotetext{
*Correspondence: Professor L Lu, Institute of Mental Health, National Clinical Research Center for Mental Disorders, Key Laboratory of Mental Health and Peking University Sixth Hospital, Peking University, 5I Huayuan Bei Road, Beijing 100191, China, Tel: +86 I0 82805308, Fax: +86 10 62032624, E-mail: linlu@bjmu.edu.cn

${ }^{5}$ These authors contributed equally to this work.

Received 17 January 2016; revised 28 March 2016; accepted 12 April 2016; accepted article preview online 22 April 2016
}

mediate resistance to stress is important for identifying new therapeutic targets for depression.

Alterations in the medial prefrontal cortex (mPFC), a region that is sensitive to the detrimental effects of stress exposure, are implicated in the pathophysiology of depression (Arnsten, 2009). Chronic stress dampens mPFC glutamate transmission (Yuen et al, 2012) and causes the dendritic atrophy of PFC neurons (Bloss et al, 2011; Duman and Duman, 2015), consistent with decreases in PFC volume that have been reported in imaging studies of MDD patients (Drevets et al, 1997; Rajkowska et al, 1999). Moreover, the optogenetic activation of mPFC produces an antidepressantlike effect in mice that are subjected to chronic social defeat (Covington et al, 2010; Vialou et al, 2014), indicating that the $\mathrm{mPFC}$ may have an important role in regulating stress vulnerability.

The ephrin family of receptors is the largest class of receptor tyrosine kinases and classified as EphA and EphB according to the type of ligands to which they bind (Himanen and Nikolov, 2003). Ephrins are membraneattached ligands that bind to Eph receptors and activate their tyrosine kinase catalytic domain. Ephrins and their receptors have critical roles in axon guidance (Brambilla and Klein, 1995) and topographic mapping in the developing nervous system (Klein, 2004). Ephrins and their receptors are also 
highly expressed in the adult nervous system. In mature brain synapses, EphB2 is enriched in large dendritic shafts and dendritic spines in the frontal cortex and hippocampus (Bouvier et al, 2008) and participate in regulating the distribution of glutamate receptors (GluRs) and formation of excitatory synapses (Kayser et al, 2006). EphB2 downregulation leads to deficits in both the formation and maintenance of mature dendritic spines (Ethell et al, 2001; Irie and Yamaguchi, 2002; Shi et al, 2009). EphB2 also regulates synapse plasticity and contributes to emotional behaviors and cognitive deficits (Attwood et al, 2011; Cisse et al, 2011). However, still unknown is whether EphB2 regulates the vulnerability to stress.

In the present study, we investigated the role of EphB2 in the $\mathrm{mPFC}$ in regulating structural plasticity and vulnerability to stress in a model of chronic social defeat stress. Uncovering the molecular mechanisms that underlie resistance to stress may have therapeutic benefits for depression.

\section{MATERIALS AND METHODS}

\section{Animals}

Male C57BL/6 mice (6-8 weeks old) and male CD1 retired breeder mice (8-months old) were obtained from the Peking University Experimental Animal Center. The mice were housed under constant temperature $\left(23 \pm 2{ }^{\circ} \mathrm{C}\right)$ and humidity $(50 \pm 5 \%)$ and maintained on a $12 \mathrm{~h} / 12 \mathrm{~h}$ light/dark cycle with free access to food and water. All of the procedures were performed with approval from the Biomedical Ethics Committee for Animal Use and Protection of Peking University and in accordance with the National Institutes of Health Guide for the Care and Use of Laboratory Animals. All of the behavioral tests and drug administrations were performed during the animals' dark phase.

\section{Drugs}

EphrinB1/Fc chimera from mouse (purity >95\%) was purchased from Sigma (St Louis, MO, USA). To prepare clustered EphrinB1/Fc, $20 \mu \mathrm{g}$ recombinant mouse EphrinB1Fc chimera, which connects mouse EphrinB1 to the Fc portion of the human IgG1 that is histidine-tagged at the carboxyl terminus, was incubated with $48 \mathrm{mg}$ goat antihuman IgG (Fc) antibody (Santa Cruz Biotechnology, Santa Cruz, CA, USA) in $30 \mu \mathrm{l}$ of phosphate-buffered saline (PBS) that contained $1 \%$ heat-inactivated bovine serum albumin at $4^{\circ} \mathrm{C}$ for at least $1 \mathrm{~h}$. For intracerebral injections, $0.5 \mu \mathrm{l}$ of the prepared drug that contained $0.1 \mu \mathrm{g}$ clustered Ephrin B1-Fc or IgG (Fc) was delivered (Yang et al, 2014).

\section{Design, Construction, and Validation of Adenovirus Vectors for Knockdown of EphB2}

Short-hairpin RNAs (shRNAs) were designed specifically for EphB2 (EphB2-shRNA, GGACCTTGTTTATAACATCAT; scramble, GGAATCTCATTCGATGCATAC). The construction and use of the self-complementing adenovirus vectors were based on our previous studies with minor modifications (Jian et al, 2014).

\section{Surgery and Intracranial Injections}

Sodium pentobarbital (60 mg/kg, i.p.) was used to anesthetize the mice before they were bilaterally implanted with permanent guide cannulae (outer diameter, $0.41 \mathrm{~mm}$; inner diameter, $0.25 \mathrm{~mm}$; RWD Life Science, Shenzhen, China) in the $\mathrm{mPFC}$ (anterior/posterior, $+1.75 \mathrm{~mm}$; medial/lateral, $\pm 0.75 \mathrm{~mm}$; dorsal/ventral, $-2.65 \mathrm{~mm}$ at $15^{\circ}$ angle) and orbitofrontal cortex (OFC; anterior/posterior, $+2.50 \mathrm{~mm}$; medial/lateral, $\pm 0.70 \mathrm{~mm}$; dorsal/ventral, $\quad-1.00 \mathrm{~mm}$ ) (Covington et al, 2010; Faccidomo et al, 2008). The drugs were intracranially microinjected using 10- $\mu$ l Hamilton syringes (Hamilton, Reno, NV, USA) that were connected via polyethylene-50 tubing (outer diameter, $0.61 \mathrm{~mm}$; inner diameter, $0.28 \mathrm{~mm}$; RWD Life Science) to injectors (outer diameter, $0.21 \mathrm{~mm}$; inner diameter, $0.11 \mathrm{~mm}$; RWD Life Science). For both the pharmacological and viral infusions, a total volume of $0.5 \mu \mathrm{l}$ was infused into each side over $5 \mathrm{~min}$, and the injection syringe was left in place for an additional $5 \mathrm{~min}$ to allow for diffusion. At the end of the experiments, the mice were anesthetized with sodium pentobarbital $(100 \mathrm{mg} / \mathrm{kg}$, i.p.) and transcardially perfused. Cannula placements were assessed using Nissl staining of $20-\mu \mathrm{m}$ thick sections under light microscopy. Subjects with misplaced cannulae were excluded from the statistical analysis.

\section{Chronic Social Defeat Stress Paradigm}

The chronic social defeat stress procedure was based on a previous study (Covington et al, 2011; Golden et al, 2011). C57BL/6 mice were subjected to chronic social defeat stress for 10 consecutive days. Every day, each mouse in the stressed group was introduced to the home cage of an unfamiliar resident for $5 \mathrm{~min}$ and physically defeated. Resident mice were CD1 breeders that were selected based on their attack latencies, which were reliably $<30 \mathrm{~s}$ in three consecutive screening tests. After $5 \mathrm{~min}$ of physical interaction, the residents and intruders remained in sensory contact in the resident home cage for $24 \mathrm{~h}$ but were separated by a perforated Plexiglas partition. Each mouse in the stressed group was exposed to a new resident home cage each day. Control animals were housed in pairs in one cage and also separated by a perforated Plexiglas partition. The subthreshold chronic social defeat stress procedure was identical to the normal chronic social defeat stress procedure, with the exception that the procedure lasted for 3 consecutive days. The mice were removed from the study and immediately killed if repeated defeats led to the development of open wounds that exceeded $1 \mathrm{~cm}$ or severe infection.

\section{Social Interaction Test}

The social interaction test was performed according to previously established protocols (Golden et al, 2011). C57BL/ 6 mice were placed in an open field $\left(42 \times 42 \mathrm{~cm}^{2}\right)$ with a small empty Plexiglas cage that was placed on one wall. The amount of time that the animal spent in the area around this cage was recorded over $2.5 \mathrm{~min}$. A novel CD1 mouse was then introduced into the Plexiglas cage, and the procedure was repeated. Animals that spent more time in the interaction zone when a novel target mouse was present 
compared with when the novel target mouse was absent were considered resilient, whereas animals that spent less time in the interaction zone when the novel target mouse was present were considered susceptible. The interaction ratio was calculated as the following: (interaction time, target present)/(interaction time, target absent). An interaction ratio of 1 was set as the cutoff. Mice with scores $<1$ were considered 'Susceptible', and mice with scores $\geqslant 1$ were considered 'Resilient'.

\section{Sucrose Preference Test}

The sucrose preference test was performed according to previously established protocols (Covington et al, 2009; Shi et al, 2012; Suo et al, 2013). Animals were given two bottles that contained $1 \%$ sucrose for 2 days of adaptation. After adaptation, the mice were deprived of water for $24 \mathrm{~h}$ and then subjected to the sucrose preference test. In the sucrose preference test, animals were housed in individual cages for $12 \mathrm{~h}$ and had free access to two bottles that contained $1 \%$ sucrose or water. We counterbalanced the bottles across the left and right sides of the cages throughout the experiment. The position of the two bottles was changed every $6 \mathrm{~h}$ during the test. At the end of the test, we measured sucrose and water consumption (in milliliters) and calculated sucrose preference (\%) as the ratio of sucrose consumption to sucrose plus water consumption.

\section{Novelty-Suppressed Feeding Test}

The novelty-suppressed feeding test was performed according to previously established protocols (Shen et al, 2010; Shi et al, 2012; Suo et al, 2013). Mice were deprived of food for $18 \mathrm{~h}$ and then placed in the corner of a Plexiglas box $\left(42 \times 42 \times 42 \mathrm{~cm}^{3}\right)$, and a pellet of food was placed on a white paper square $\left(6 \times 6 \mathrm{~cm}^{2}\right)$ in the center of the cage. Each test lasted $5 \mathrm{~min}$, and the latency to approach the food and begin eating was recorded (in seconds) as the main test parameter. The latency to feed was scored when the mouse sat on the paper square and bit the pellet using its forepaws. Subsequent home cage food consumption over $5 \mathrm{~min}$ was the quantitative control measure for appetite.

\section{Open Field Test}

Locomotor activity was measured using the open field test as previously described (Han et al, 2015; Xue et al, 2015). Briefly, the apparatus consisted of a $42 \times 42 \times 42 \mathrm{~cm}^{3}$ square arena that was divided into 25 equal squares $\left(8.4 \times 8.4 \mathrm{~cm}^{2}\right)$ on the floor of the arena. The mice were placed in the center of the apparatus, and the number of crossings into adjacent squares of the apparatus were counted for $5 \mathrm{~min}$.

\section{Tissue Sample Preparation}

The procedure was based on our previous studies (Chai et al, 2014; Luo et al, 2015; Xue et al, 2012). After the last behavioral test, the mice were decapitated. The brains were quickly frozen in $-60^{\circ} \mathrm{C} \mathrm{N}$-hexane, and bilateral tissue punches of the $\mathrm{mPFC}$ and OFC (8-gauge) were obtained and placed in a solution that contained $0.32 \mathrm{M}$ sucrose, $20 \mathrm{mM}$ HEPES ( $\mathrm{pH} 7.4$ ), $1 \mathrm{mM}$ ethylenediaminetetraacetic acid (EDTA), $1 \times$ protease inhibitor cocktail, $5 \mathrm{mM} \mathrm{NaF}$, and $1 \mathrm{mM}$ sodium vanadate. After being homogenized by an electrical disperser (Wiggenhauser, Sdn Bnd, Los Lunas, NM, USA), the homogenate was centrifuged for $10 \mathrm{~min}$ at 2800 rotations per minute (r.p.m.) at $4{ }^{\circ} \mathrm{C}$. The pellet that contained nuclei and large cellular debris was discarded. The supernatant was centrifuged at 12000 r.p.m. for $10 \mathrm{~min}$. After centrifugation, the supernatant (cytosolic fraction) was removed, and the pellet (crude synaptosomal fraction) was resuspended and sonicated in protein lysis buffer $(50 \mathrm{mM}$ Tris- $\mathrm{HCl}(\mathrm{pH} 7.50) 150 \mathrm{mM} \mathrm{NaCl}, 1 \%$ Triton X-100, $0.1 \%$ sodium dodecyl sulfate (SDS), $2 \mathrm{mM} \mathrm{EDTA,} 1 \mathrm{mM} \mathrm{NaVO}$, $5 \mathrm{mM} \mathrm{NaF}$, and $1 \times$ protease inhibitor cocktail). The protein concentrations of all of the samples from the crude synaptosomal fraction were determined using the BCA assay kit (Beyotime Biotechnology, Shanghai, China).

\section{Western Blotting}

The assay procedures were based on our previous studies (Lu et al, 2005; Zhu et al, 2013). Samples from the crude synaptosomal fraction were subjected to SDS-polyacrylamide gel electrophoresis ( $12.5 \%$ acrylamide/ $0.27 \% N, N^{\prime}$-methylenebisacryalamide resolving gel) for approximately $30 \mathrm{~min}$ at $80 \mathrm{~V}$ in stacking gel and approximately $1 \mathrm{~h}$ at $120 \mathrm{~V}$ in resolving gel. Proteins were electrophoretically transferred to Immobilon-P transfer membranes (Millipore, Bedford, MA, USA) at $0.25 \mathrm{~A}$ for $3 \mathrm{~h}$. The membranes were washed with TBST (Tris-buffered saline plus $0.05 \%$ Tween-20, pH 7.4) before dipping in blocking buffer (5\% skimmed dry milk in TBST) overnight at $4{ }^{\circ} \mathrm{C}$. The membranes were then incubated for $1 \mathrm{~h}$ at room temperature with anti-EphB2 antibody (1:1000; Abcam, Cambridge, UK; catalog no. 5418), antiphospho-cofilin antibody (1:1000; Abcam; catalog no. 12866), anti-cofilin antibody ( 1 : 1000; Abcam; catalog no. 42824), antiGluR1 antibody (1: 1000; Abcam; catalog no. ab109450), antiGluR2 antibody (1:1000; Abcam; catalog no. ab52932), anti-PSD95 antibody (1:1000; Abcam; catalog no. ab18258), anti-Synapsin I antibody (1:1000; Abcam; catalog no. ab64581), or anti-GAPDH antibody ( $1: 1000$, Abcam; catalog no.181602). After shaking in $4 \times 6$ min washes in TBST buffer, the blots were incubated for $45 \mathrm{~min}$ at room temperature with horseradish peroxidase-conjugated secondary antibody (goat anti-rabbit or mouse IgG; Santa Cruz Biotechnology and Vector Labs, respectively) diluted 1:3000 in blocking buffer. The blots were then shaken in $4 \times 6 \mathrm{~min}$ washes in TBST. Afterward, the blots were incubated with a layer of Super Signal enhanced chemiluminescence substrate mixture (Pierce Biotechnology, Rockford, IL, USA) for $1 \mathrm{~min}$ at room temperature. The excess mixture was dripped off before the blots were wrapped with a clean piece of plastic wrap (no bubbles between blot and wrap), and the blots were then screened using the ChemiDoc MP System (Bio-Rad, Hercules, CA, USA) for 5-60 s. The band intensities were quantified with th Quantity One 4.4.0 software from Bio-Rad (Hercules, CA, USA).

\section{Golgi-Cox Staining}

The Golgi-Cox impregnation procedure was based on a previous study (Han et al, 2015; Restivo et al, 2005). The mice were perfused with $0.9 \%$ saline, and the brains were 
removed and placed in Golgi-Cox solution (1.04\% potassium dichromate, $1.04 \%$ mercury chloride, and $0.83 \%$ potassium chromate, dissolved in double-distilled water) at room temperature for 14 days. The solution was refreshed every 3 days, immersed in a $30 \%$ sucrose solution for 5 days, and then coronally sectioned $(100 \mu \mathrm{m})$ using a vibratome. Staining was developed by a 1-min rinse in water, $30 \mathrm{~min}$ in $16 \%$ ammonia, and a 1 -min rinse in water followed by dehydration for $1 \mathrm{~min}$ in 50\% ethanol, $1 \mathrm{~min}$ in $70 \%$ ethanol, $1 \mathrm{~min}$ in $90 \%$ ethanol, $1 \mathrm{~min}$ in $100 \%$ ethanol, and $15 \mathrm{~min}$ in CXA solution (trichloromethane:dimethylbenzene:ethanol, $1: 1: 1)$. The sections were then coated with transparent xylene and sealed with neutral balsam.

All of the images were captured with an Olympus BX53 microscope using a $\times 100$ oil-immersion objective. For the quantitative analysis of spine density, the spines were counted along dendritic segments that were chosen from secondary and tertiary dendrites. Dendrite length was measured using the NIH ImageJ software, and the number of dendritic spines was counted by two trained observers who were blind to the experimental conditions. The average number of spines per $10 \mu \mathrm{m}$ of dendrite was calculated. For each group, we examined 6-10 neurons per mouse and 3-5 mice per group. Three segments for each neuron were selected for analysis.

\section{Histology}

After the behavioral experiments, the mice were anesthetized and perfused with $0.01 \mathrm{M}$ PBS and $4 \%$ paraformaldehyde, $\mathrm{pH}$ 7.4. The brains were then extracted and postfixed in $4 \%$ paraformaldehyde for $24 \mathrm{~h}$. Subsequently, the brains were cryoprotected in $30 \%$ sucrose in $0.2 \mathrm{M}$ phosphate buffer and frozen.

Cannula placements were assessed using Nissl staining with a section thickness of $20 \mu \mathrm{m}$ under light microscopy. The locations of the cannulae are shown in Supplementary Figure S8. Additionally, the brains were coronally sectioned at $20 \mu \mathrm{m}$ using a sliding microtome, and the brain slices were counterstained with DAPI and examined using an Olympus BX53 fluorescent microscope to evaluate enhanced green fluorescent protein expression in the mPFC and OFC (Han et al, 2015; Xue et al, 2015). Mice with misplaced cannulae were excluded from the statistical analysis.

\section{Statistical Analysis}

All of the statistical analyses were performed using the SPSS 17.0 software (SPSS, Chicago, IL, USA). The data are expressed as mean \pm SEM and were analyzed using analysis of variance (ANOVA) with appropriate between- and within-subject factors for each experiment (see Results section). Significant main effects and interactions $(p<0.05)$ in the factorial ANOVAs were further analyzed using oneway ANOVAs and Least Significant Difference post hoc tests.

\section{RESULTS}

\section{Chronic Social Defeat Stress Decreased EphB2 Signaling in the MPFC in Susceptible Mice}

Chronic social defeat stress is an etiologically valid approach to model the symptomatology of stress-related disorders and can distinguish between the susceptible and resilient individuals (Golden et al, 2011; Krishnan et al, 2007). We first examined the effects of chronic social defeat stress on EphB2 and its downstream signaling. Mice were randomly assigned to a non-stressed group and stressed group. The stressed group was subjected to 10 consecutive days of chronic social defeat stress, and mice in the non-stressed group were normally housed in their home cages for 10 days. The mice then underwent the social interaction test, and stressed mice were divided into resilient and susceptible subgroups according to their different behavioral performance. Subsequently, all three groups underwent the sucrose preference test and novelty-suppressed feeding test 1 and 2 days after the social interaction test (Figure 1a).

Stressed mice were divided into susceptible and resilient groups based on the measure of social avoidance, in which susceptible animals exhibited a significant reduction of social interaction compared with both the non-stressed and resilient groups (one-way ANOVA, $\mathrm{F}_{2,40}=15.655, p<0.05$; Figure 1b, left column). Multivariate ANOVAs revealed that susceptible mice spent less time in the interaction zone (phenotype $\times$ target interaction, $\mathrm{F}_{2,76}=16.825, \quad p<0.05$; Figure $1 \mathrm{~b}$, right column) and more time in the corner zone (phenotype $\times$ target interaction, $\mathrm{F}_{2,76}=19.617, \quad p<0.05$; Supplementary Figure S1A) when the target was present compared with the non-stressed group. Compared with the non-stressed group, the susceptible group presented anhedonia in the sucrose preference test (one-way ANOVA, $\mathrm{F}_{2,40}=16.357, p<0.05$; Figure $1 \mathrm{c}$, left column) and anxietylike behavior in the novelty-suppressed feeding test (one-way ANOVA, $F_{2,40}=14.519, p<0.05$; Figure 1d, left column). Chronic social defeat stress did not alter fluid consumption $(p>0.05$; Figure 1c, right column) or total food intake ( $p>0.05$; Figure 1d, right column) in the three groups. These results indicate that susceptible mice exhibited a depressionlike phenotype.

We found that chronic social defeat stress significantly decreased EphB2 levels in the $\mathrm{mPFC}$ in susceptible mice (one-way ANOVA, $\mathrm{F}_{2,36}=25.98, p<0.05$; Figure 1e) but not in resilient mice. Previous studies showed that EphB2 regulates cofilin activity (Shi et al, 2009; Simon et al, 2009). Therefore, we next examined the phosphorylation of cofilin in the $\mathrm{mPFC}$ and OFC after chronic social defeat stress. The one-way ANOVA revealed that chronic social defeat stress significantly reduced the phosphorylation of cofilin $\left(\mathrm{F}_{2,36}=31.59, p<0.05\right.$; Figure $\left.1 \mathrm{e}\right)$ in the mPFC in susceptible mice. A previous study showed that synaptic strength and $\alpha$-amino-3-hydroxy-5-methyl-4-isoxazole-propionic acid (AMPA) receptor regulation mediate stress resilience (Vialou et al, 2010). Thus we examined the expression of postsynaptic density (PSD95), synapsin I, GluR1, and GluR2 after chronic social defeat stress. The one-way ANOVA revealed that chronic social defeat stress decreased the expression of PSD95 $\left(F_{2,36}=9.42, p<0.05\right.$; Figure 1e), synapsin I $\left(\mathrm{F}_{2,36}=12.19, p<0.05 ;\right.$ Figure 1e), GluR1 $\left(\mathrm{F}_{2,36}=30.15, p<0.05\right.$; Figure $\left.1 \mathrm{e}\right)$, and GluR2 $\left(\mathrm{F}_{2,36}=58.60\right.$, $p<0.05$; Figure 1e) in the mPFC in susceptible mice but not in resilient mice (all $p>0.05$; Figure 1e).

Additionally, chronic social defeat stress had no effect on the expression of EphB2, the phosphorylation of cofilin, cofilin, PSD95, synapsin I, or membranous GluR1 or GluR2 in the OFC (all $p>0.05$; Figure 1f). These results indicate 
a

Timeline

$\underbrace{\begin{array}{c}\text { Chronic social } \\ \text { defeat stress }\end{array}}_{\text {D1 - D10 }} \Rightarrow \underbrace{\begin{array}{c}\text { Social interaction } \\ \text { test }\end{array}}_{\text {D11 }} \Rightarrow \underbrace{\text { SPT }}_{\text {D12 }} \Rightarrow \underbrace{\text { NSFT }}_{\text {D13 }} \Rightarrow \underbrace{\begin{array}{c}\text { Quantification analysis } \\ \text { of protein }\end{array}}_{\text {D14 }}$

b Social interaction test
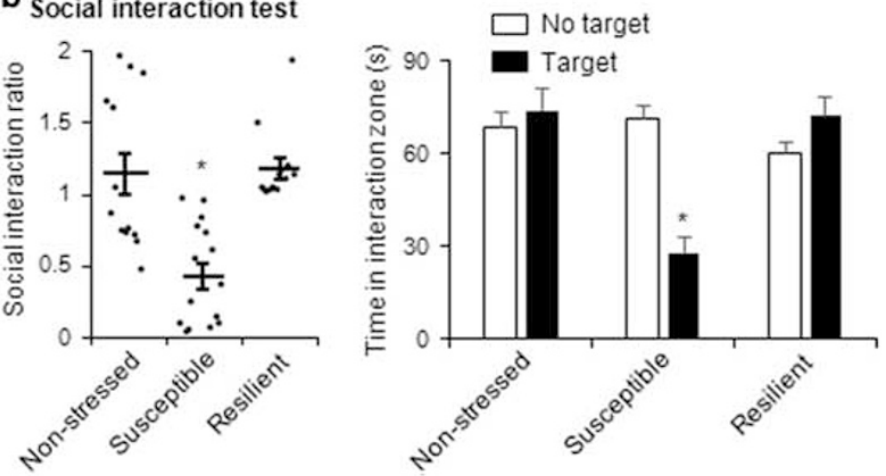

C Sucrose preference test
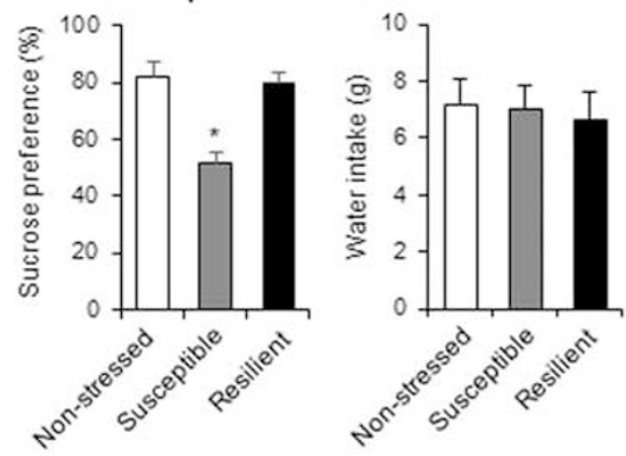

d Novelty suppressing feeding test

Protein levels in mPFC
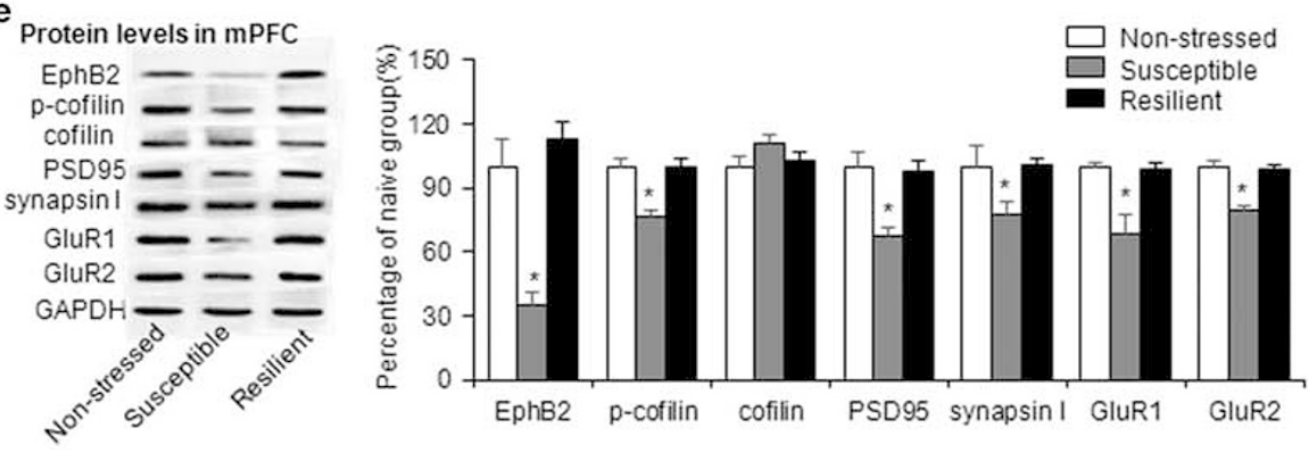

f
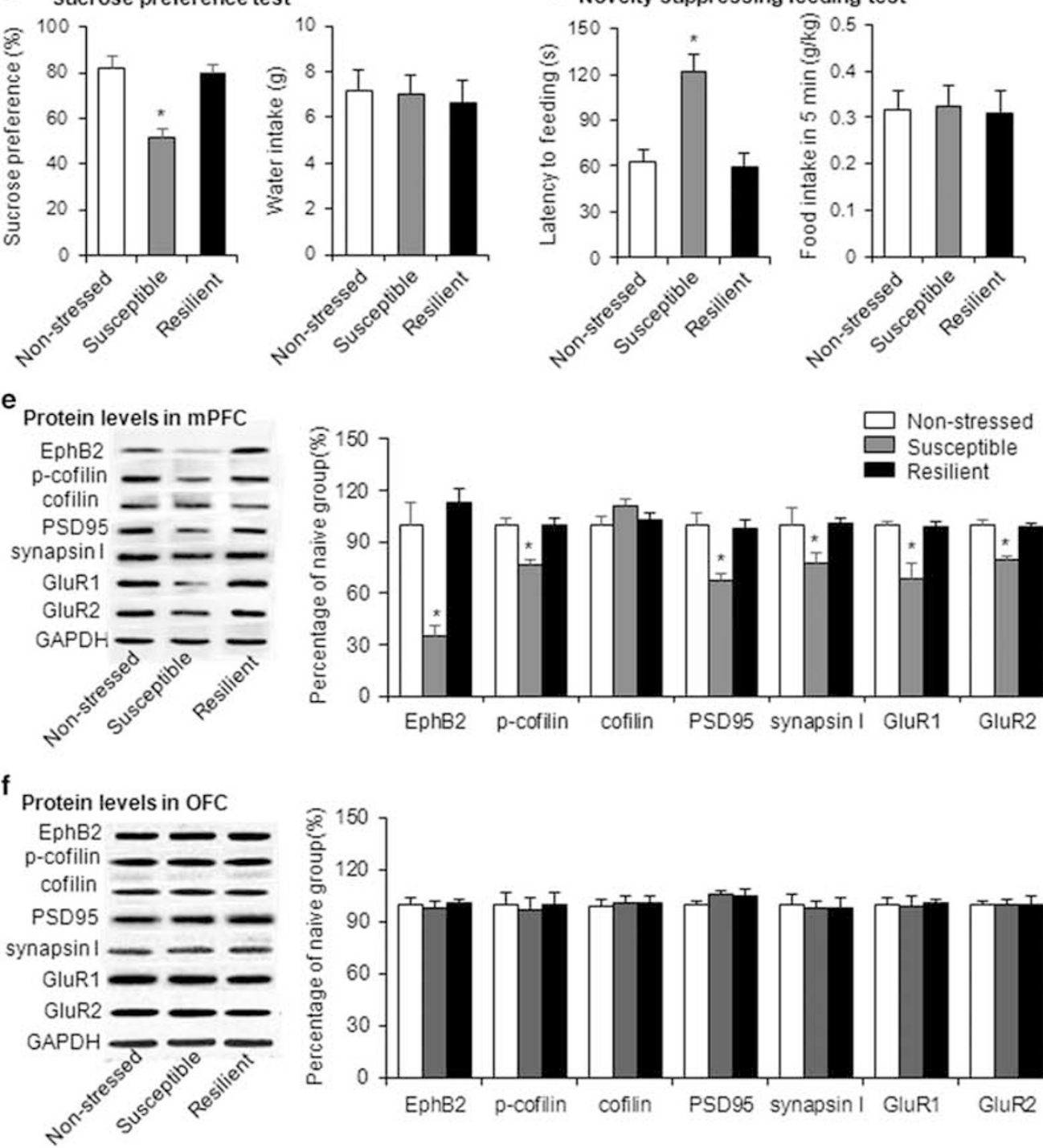

Figure I Chronic social defeat stress decreased EphB2 signaling in the mPFC in susceptible mice. (a) Experimental timeline of chronic social defeat stress. (b) Social interaction ratio and time spent in the interaction zone in the social interaction test. (c) Sucrose preference and water intake in the sucrose preference test (SPT). (d) Latency to feed and food intake over $5 \mathrm{~min}$ in the novelty-suppressed feeding test (NSFT) after 10 days of chronic social defeat stress ( $n=13-15$ per group). $(e, f)$ EphB2 and downstream protein levels and representative westem blottings in the mPFC and OFC after chronic social defeat stress ( $n=10-14$ per group). The downstream proteins included phosphorylated coflin, cofilin, PSD95, synapsin I, and membranous GluRI and GluR2. *p <0.05, compared with the non-stressed group. 
that the susceptibility to stress is associated with a decrease in EphB2 signaling in the mPFC but not in the OFC.

\section{Activation of EphB2 in the mPFC Reversed the Susceptibility to Stress}

We next examined the effects of EphB2 activation on depressive-like behaviors after chronic social defeat stress. EphrinB1/Fc and PBS/Fc were constructed and microinfused in the $\mathrm{MPFC}$ or OFC in both susceptible and non-stressed mice. The mice were then subjected to the social interaction test, sucrose preference test, and novelty-suppressed feeding test $1 \mathrm{~h}$ after the infusions (Figure 2a) and 10 days after the infusions (Figure 3a). One hour after the intra-mPFC microinjection of EphrinB1/Fc, the social interaction ratio was significantly increased in the susceptible group (two-way ANOVA, main effect of stress, $F_{1,39}=13.683, p<0.05$; main effect of drug, $\mathrm{F}_{1,39}=24.007, p<0.05$; stress $\times$ drug interaction, $\mathrm{F}_{1,39}=8.404, p<0.05$; Figure $2 \mathrm{~b}$, left column), and a similar effect was found 10 days after the infusions of EphrinB1/Fc (two-way ANOVA, main effect of stress, $\mathrm{F}_{1,39}=10.228, p<0.05$; main effect of drug, $\mathrm{F}_{1,39}=5.629$, $p<0.05 ; \quad$ stress $\times$ drug interaction, $\mathrm{F}_{1,39}=5.394, \quad p<0.05$; Figure $3 \mathrm{~b}$, left column). Multivariate ANOVAs revealed that the susceptible mice that received EphrinB1/Fc microinjections spent more time in the interaction zone $(1 \mathrm{~h}$ after infusion: stress $\times$ drug $\times$ target interaction, $F_{1,78}=13.999$, $p<0.05$, Figure $2 b$, right column; 10 days after infusion: stress $\times$ drug $\times$ target interaction, $\mathrm{F}_{1,78}=9.556, \quad p<0.05$, Figure $3 \mathrm{~b}$, right column) and spent less time in the corner zone $(1 \mathrm{~h}$ after infusion: stress $\times$ drug $\times$ target interaction, $\mathrm{F}_{1,78}=6.903, p<0.05$, Supplementary Figure S2B; 10 days after infusion: stress $\times$ drug $\times$ target interaction, $F_{1,78}=$ 10.927, $p<0.05$, Supplementary Figure S3B) when the target was present compared with susceptible mice that received PBS/Fc microinjections. The microinjection of EphrinB1/Fc in the $\mathrm{mPFC}$ also produced antidepressant- and anxiolyticlike effects in the sucrose preference test and noveltysuppressed feeding test $1 \mathrm{~h}$ after infusion (Figure $2 \mathrm{c}$ and $\mathrm{d}$ ) and 10 days after infusion (Figure $3 c$ and $d$ ). The EphrinB1/ Fc microinjected mice exhibited higher sucrose preference ( $1 \mathrm{~h}$ after infusion: two-way ANOVA, stress $\times$ drug interaction, $\mathrm{F}_{1,39}=13.699, p<0.05$, Figure $2 \mathrm{c} ; 10$ days after infusion: two-way ANOVA, stress $\times$ drug interaction, $F_{1,39}=9.429$, $p<0.05$, Figure $3 c$ ). The microinjection of EphrinB1/Fc also reversed the stress-induced increase in the latency to feed (two-way ANOVA, stress $\times$ drug interaction, $\mathrm{F}_{1,39}=8.165$, $p<0.05$; Figure 2d), and similar effect was found 10 days after infusion (two-way ANOVA, stress $\times$ drug interaction, $\mathrm{F}_{1,39}=6.622, p<0.05$; Figure $3 \mathrm{~d}$ ). Locomotor activity was unaffected by the EphrinB1/Fc infusions (Figures $2 \mathrm{e}$ and $3 \mathrm{e}$ ). The microinfusion of EphrinB1/Fc in the OFC in susceptible mice had no effect on social avoidance, depressive-, or anxiety-like behavior in the social interaction test, sucrose preference, or novelty-suppressed feeding (all $p>0.05$; Figure 4 and Supplementary Figure S4). These results indicate that EphB2 in the mPFC but not in the OFC mediates stress-resistant, antidepressant, and anxiolytic responses.

We next investigated the potential mechanisms that underlie the pro-resilient effect of EphB2 activation. We measured the expression of downstream proteins of EphB2 in the mPFC after the EphrinB1/Fc microinfusion (Figure 2a). The activation of EphB2 in the mPFC reversed the decrease in $\mathrm{p}$-cofilin (two-way ANOVA, stress $\times$ drug interaction, $F_{1,36}=48.53, p<0.05$; Figure $2 \mathrm{f}$ ) that was induced by chronic social defeat stress in the susceptible group but not in the non-stressed group. The decreases in synaptic proteins that are associated with synaptic strength, including PSD95 (two-way ANOVA, stress $\times$ drug interaction, $F_{1,36}=9.29, p<0.05$; Figure $2 \mathrm{f}$ ), synapsin I (two-way ANOVA, stress $\times$ drug interaction, $F_{1,36}=16.902, p<0.05$; Figure 2f), GluR1 (two-way ANOVA, stress $\times$ drug interaction, $F_{1,36}=28.83, p<0.05$; Figure 2f), and GluR2 (two-way ANOVA, stress $\times$ drug interaction, $F_{1,36}=28.46, p<0.05$; Figure $2 \mathrm{f}$ ), were also rescued by EphB2 activation.

The increases in the expression of $\mathrm{p}$-cofilin (two-way ANOVA, stress $\times$ drug interaction, $\left.F_{1,36}=33.65, p<0.05\right)$, PSD95 (two-way ANOVA, stress $\times$ drug interaction, $\mathrm{F}_{1,36}=$ 12.87, $p<0.05$ ), synapsin I (two-way ANOVA, stress $\times$ drug interaction, $\left.F_{1,36}=13.29, p<0.05\right)$, membrane GluR1 (two-way ANOVA, stress $\times$ drug interaction, $\mathrm{F}_{1,36}=18.05$, $p<0.05$ ), and membrane GluR2 (two-way ANOVA, stress $\times$ drug interaction, $\mathrm{F}_{1,36}=14.88, p<0.05$ ) were also found 10 days after EphrinB1/Fc application, which may explain the prolonged behavioral effects of EphB2 activation in the mPFC (Figure 3f).

\section{Reduction of EphB2 in the mPFC Promoted Stress Susceptibility}

To further investigate the impact of EphB2 knockdown on stress vulnerability, we utilized a subthreshold chronic social defeat stress paradigm that did not induce depressive-like behaviors. We first examined the efficiency of EphB2 knockdown by adenovirus-mediated shRNA (Figure 5b). One week after the infusion of $A d V_{\text {shEphB2 }}$ or $A d V_{\text {Scramble }}$ in the $\mathrm{mPFC}$, the mice were decapitated for the western blotting assays (Figure 5a). We found that EphB2 expression levels in the mPFC were significantly decreased in the $A_{d V}$ shRnA group compared with the $\mathrm{AdV}_{\text {Scramble }}$ group (one-way ANOVA, $F_{1,15}=40.63, p<0.05$; Figure 5c). A similar decrease in EphB2 expression was detected in the OFC after local AdV-shEphB2 infusion (one-way ANOVA, $\mathrm{F}_{1,15}=$ 50.12, $p<0.05$; Figure 6a and b).

Mice that received $A d V_{\text {shRNA }}$ or $A d V_{\text {Scramble }}$ infusion in the mPFC were subjected to subthreshold chronic social defeat stress and underwent behavioral tests on the following 3 days (Figure $5 \mathrm{~d}$ ). The mice that received an intra-PFC infusion of $A d V_{\text {shRNA }}$ exhibited significant social avoidance in the social interaction test (two-way ANOVA, stress $\times$ vector interaction, $\mathrm{F}_{1,39}=4.280, p<0.05$; Figure $5 \mathrm{e}$ ), anhedonia in the sucrose preference test (two-way ANOVA, stress $\times$ vector interaction, $F_{1,39}=4.795, p<0.05$; Figure $5 f$ ), and anxiety-like behavior in the novelty-suppressed feeding test (two-way ANOVA, stress $\times$ vector interaction, $\mathrm{F}_{1,39}=6.622, p<0.05$; Figure $5 \mathrm{~g}$ ) after subthreshold social defeat stress. Multivariate ANOVAs revealed that subthreshold-stressed mice that received $A_{d V} V_{\text {shRNA }}$ microinjections spent less time in the interaction zone (stress $\times$ vector $\times$ target interaction, $F_{1,78}=2.941, p=0.09$; Supplementary Figure S5A) and spent more time in the corner zone (stress $\times$ vector $\times$ target interaction, $F_{1,78}=6.654, p<0.05$; Supplementary Figure S5B) when the target was present 
Timeline

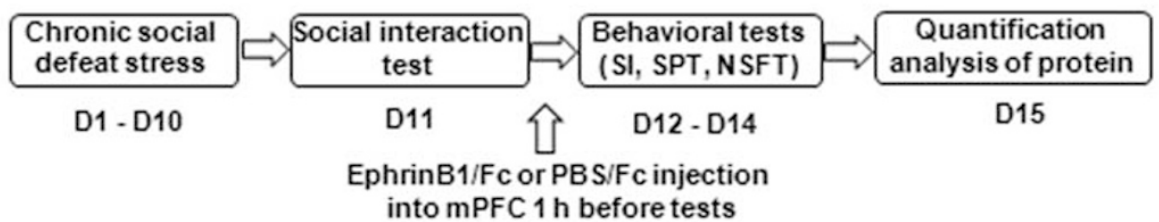

b Social interaction test
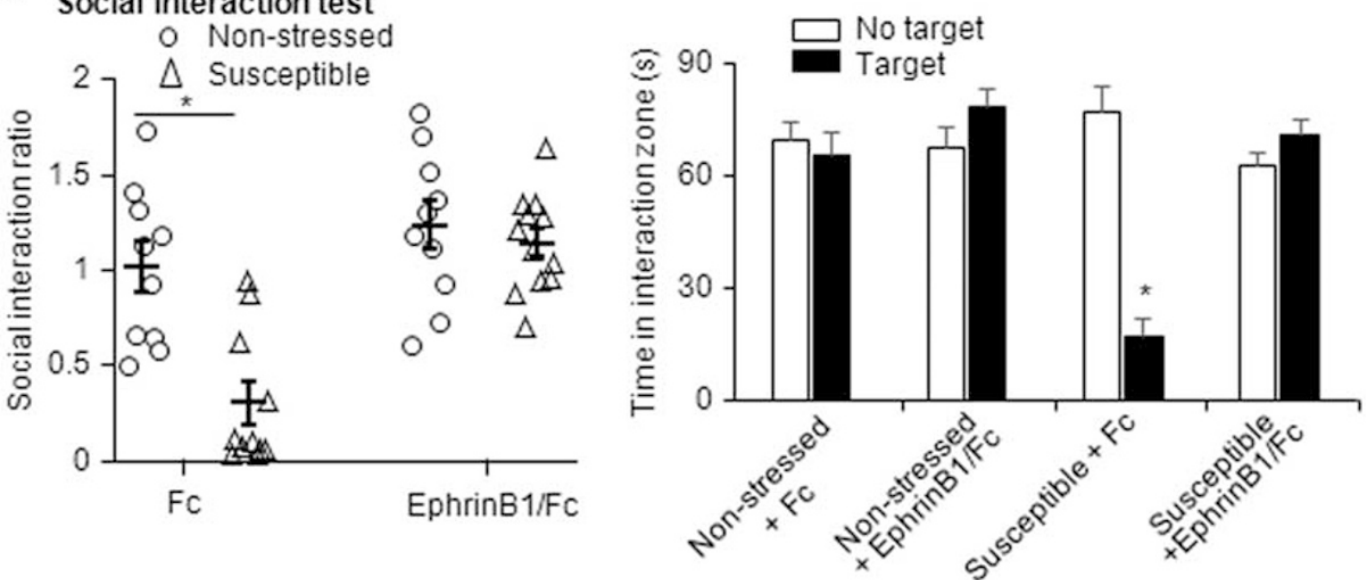

C

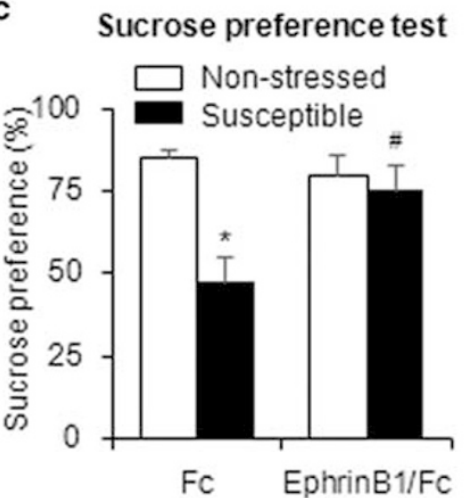

d

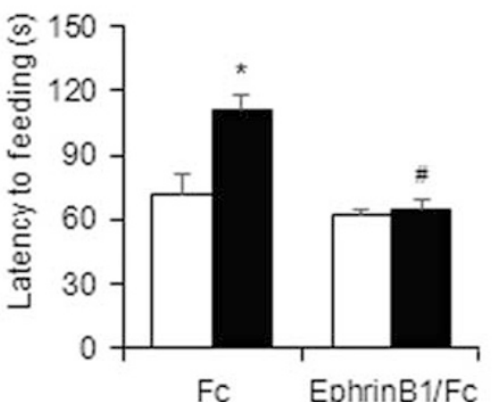

e

Locomotor activity

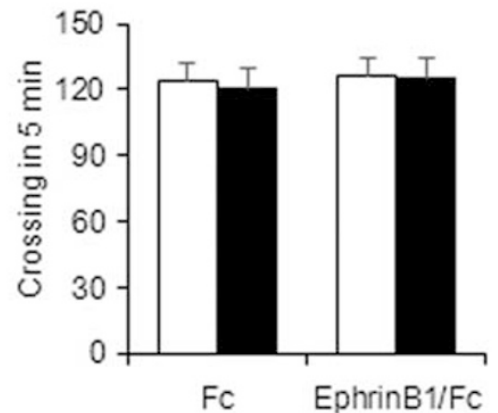

f Protein levels in mPFC
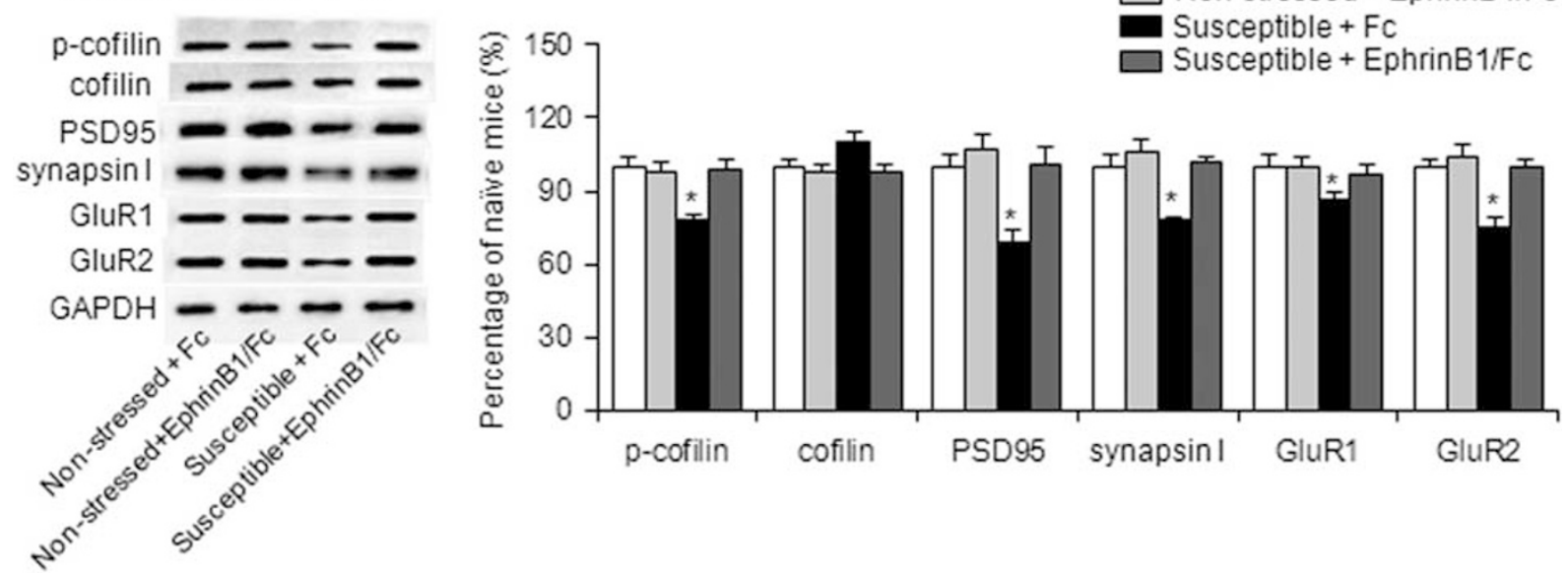

Figure 2 Activation of EphB2 in the mPFC improved depressive-like behaviors in susceptible mice. (a) Experimental timeline of chronic social defeat stress and EphrinBI/Fc microinjection in the mPFC I h before the behavioral tests. (b) Social interaction ratio and time spent in the interaction zone in the social interaction (SI) test. (c) Sucrose preference in the sucrose preference test (SPT). (d) Latency to feed over 5 min in the novelty-suppressed feeding test (NSFT). (e) Number of crossings during the $5 \mathrm{~min}$ open field test I h after EphrinBI/Fc microinjection in the $\mathrm{mPFC}(n=10-12$ per group). (f) EphB2 downstream proteins levels in the mPFC and representative western blottings I h after the microinjection ( $n=9-1 \mid$ per group). The EphB2 downstream proteins included phosphorylated cofilin, cofilin, PSD95, synapsin I, and membranous GluRI and GluR2. ${ }^{*} p<0.05$, compared with the non-stressed Fc group; \#p <0.05, compared with the susceptible Fc group. 
compared with subthreshold-stressed mice that received $A d V_{\text {Scramble }}$ microinjections. Mice that received $A d V_{\text {Scramble }}$ did not exhibit these depressive-like behaviors after subthreshold social defeat stress (all $p>0.05$; Figure $5 \mathrm{e}-\mathrm{g}$ ).
Locomotor activity was unaffected by EphB2 knockdown via adenovirus-mediated shRNA (Supplementary Figure S5D). EphB2 knockdown in the OFC had no significant effects on social interaction, sucrose preference, or the latency to feed

a Timeline

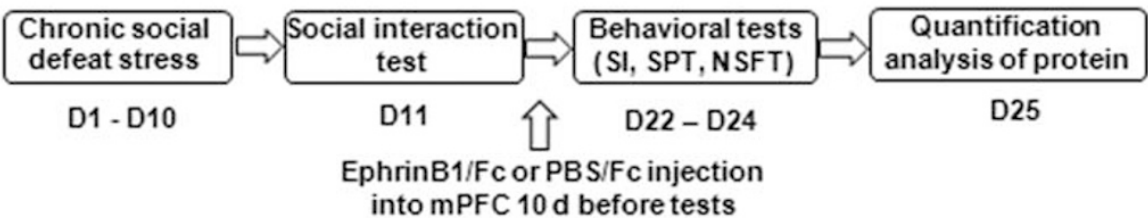

b
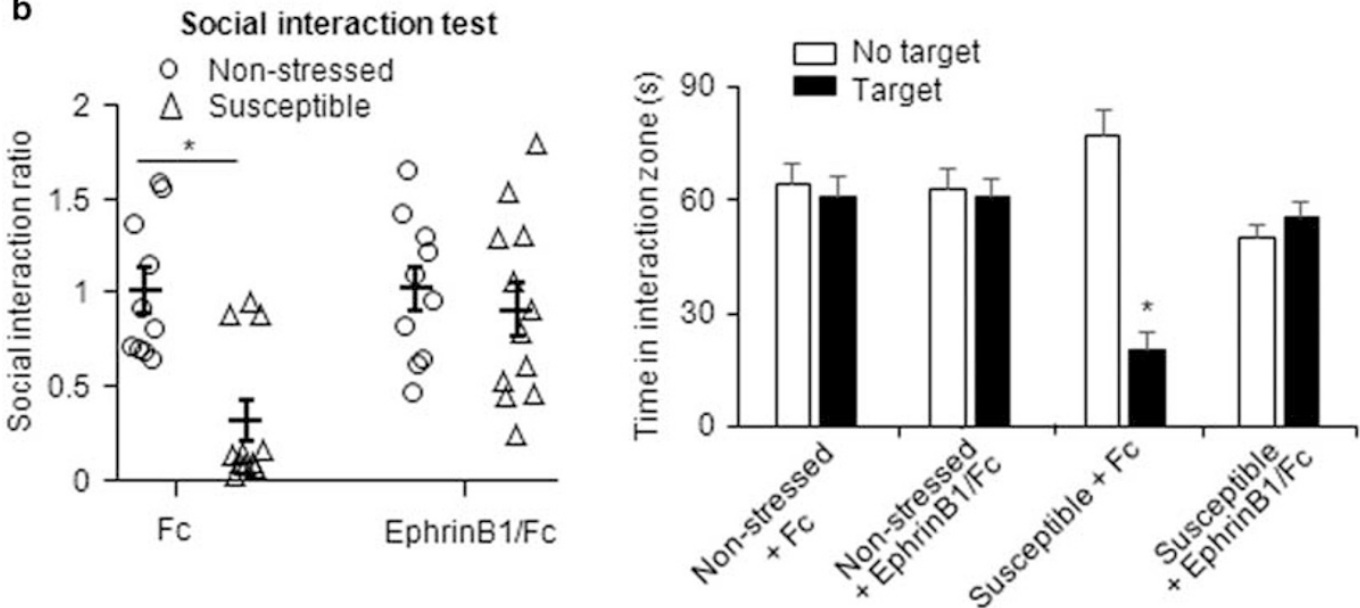

C

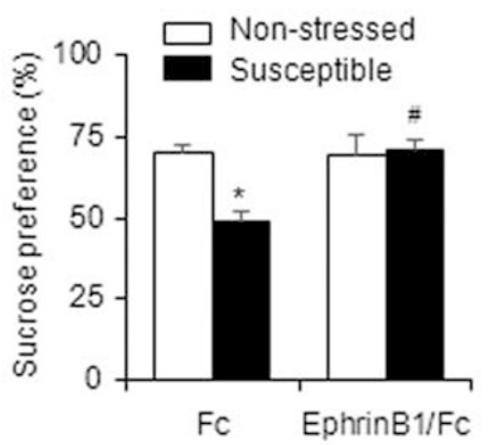

d

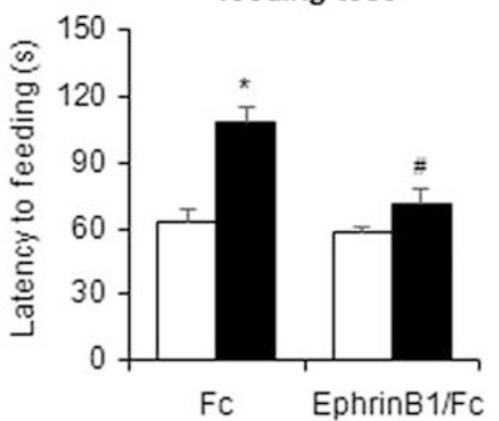

Novelty suppressed feeding test e

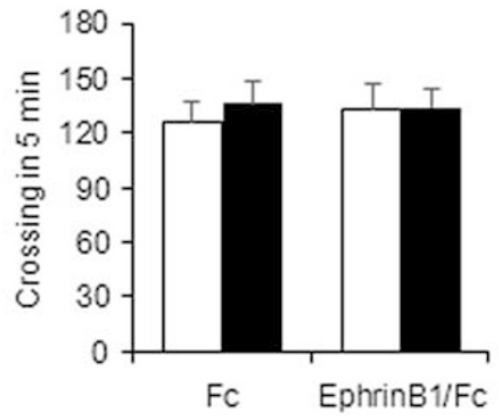

$f$ Protein levels in mPFC
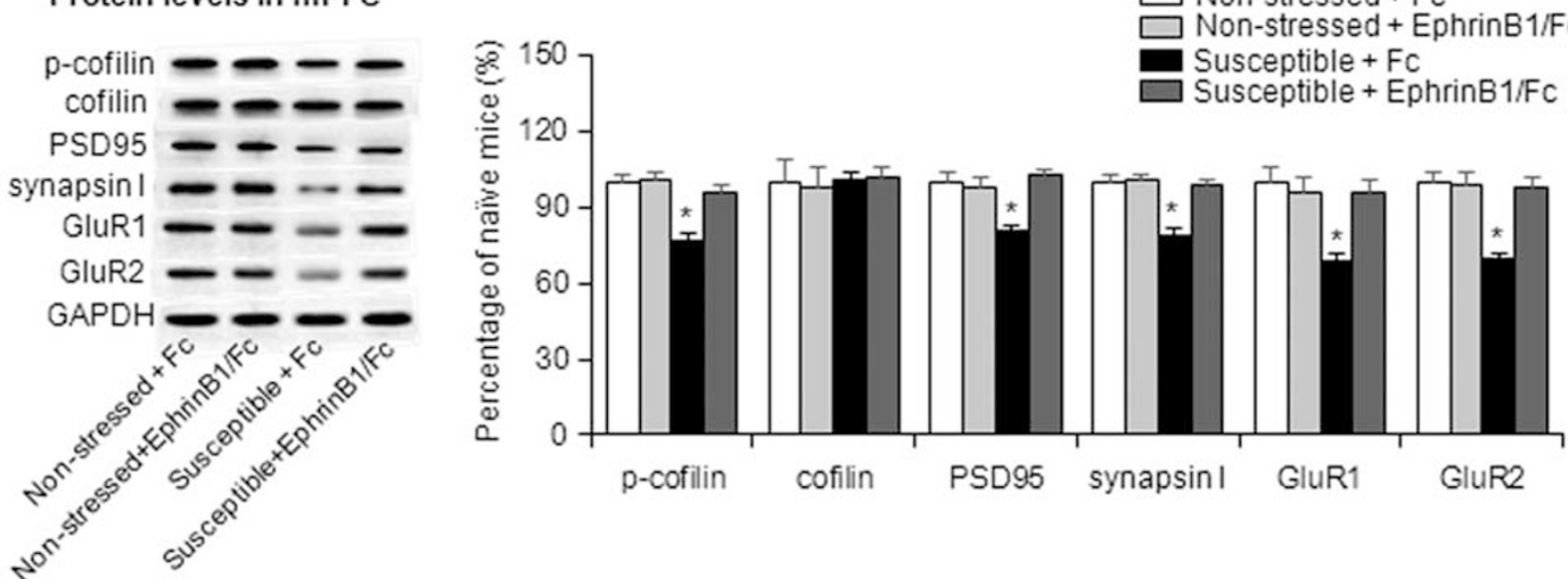
after subthreshold social defeat stress (all $p>0.05$; Figure $6 \mathrm{c}-\mathrm{e}$ and Supplementary Figure S6A and B).

We next examined the molecular mechanisms that are responsible for the increase in the susceptibility to stress
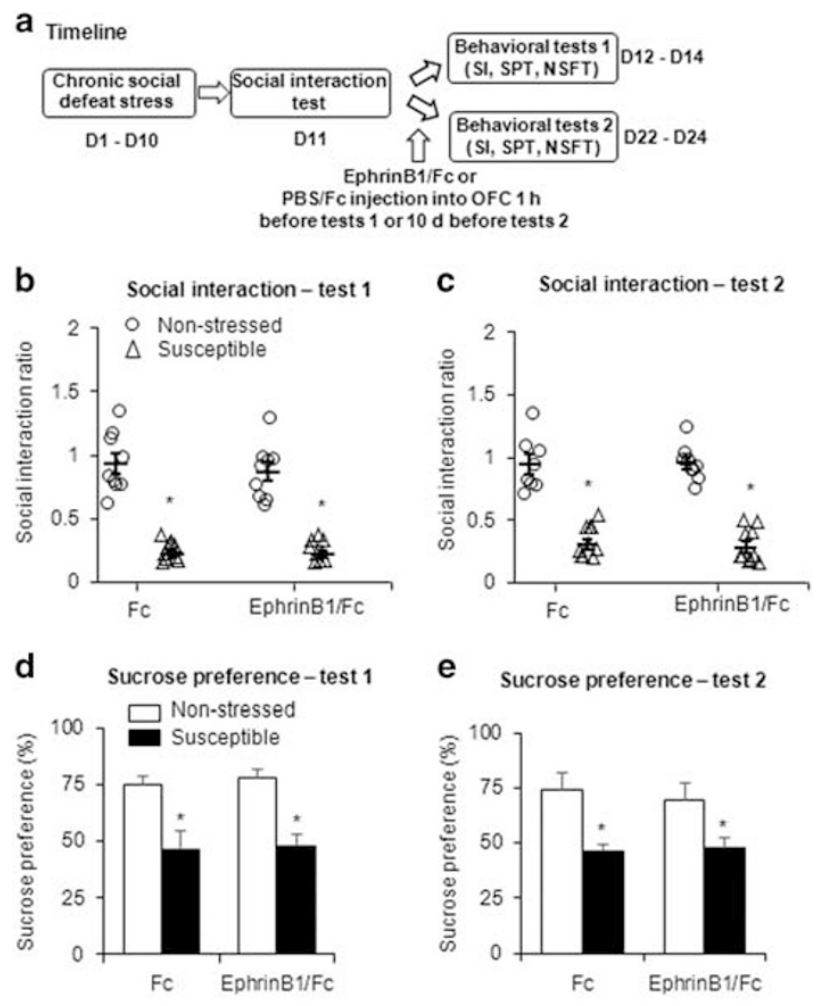

e sucrose preference-test 2
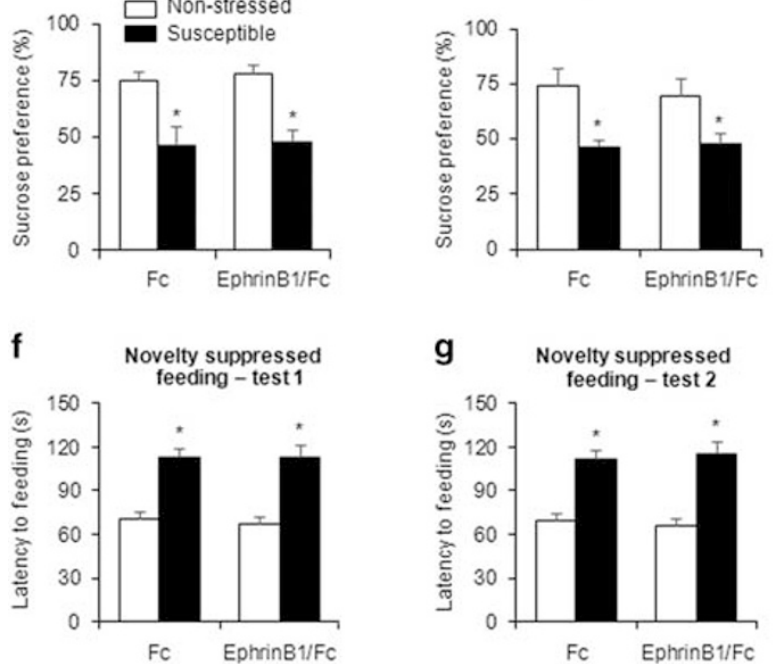

Figure 4 Activation of EphB2 in the OFC did not change depressive-like behaviors in susceptible mice. (a) Experimental timeline of EphrinBI/Fc microinjection and chronic social defeat stress. (b) Social interaction ratio in the social interaction (SI) test. (d) Sucrose preference in the sucrose preference test (SPT). ( $f$ ) Latency to feed over $5 \mathrm{~min}$ in the noveltysuppressed feeding test (NSFT) I h after EphrinBI/Fc microinjection in the OFC (tests I). (c) Social interaction ratio in the SI test. (e) Sucrose preference in the SPT. (g) Latency to feed over 5 min in the NFST I 0 days after EphrinBI/Fc microinjection in the OFC (tests 2). $* p<0.05$, compared with the non-stressed Fc group. $n=8-10$ per group. after EphB2 knockdown. We found that $\mathrm{AdV}_{\text {shRNA }}$ microinjection decreased the EphB2 expression levels in both the non-stressed groups and subthreshold stress groups (twoway ANOVA, stress $\times$ vector interaction, $F_{1,37}=46.79$, $p<0.05$; Figure $5 \mathrm{~h})$. EphB2 knockdown by $\mathrm{AdV}_{\text {shRNA }}$ microinfusion also decreased the expression of p-cofilin (two-way ANOVA, stress $\times$ vector interaction, $\mathrm{F}_{1,37}=42.44$, $p<0.05$; Figure 5h), PSD95 (two-way ANOVA, stress $\times$ vector interaction, $\mathrm{F}_{1,37}=20.51, \quad p<0.05$; Figure $5 \mathrm{~h}$ ), synapsin I (two-way ANOVA, stress $\times$ vector interaction, $\mathrm{F}_{1,37}=10.42, \quad p<0.05 ; \quad$ Figure 5h), GluR1 (two-way ANOVA, stress $\times$ vector interaction, $\mathrm{F}_{1,37}=21.96, p<0.05$; Figure 5h), and GluR2 (two-way ANOVA, stress $\times$ vector interaction, $F_{1,37}=28.12, p<0.05$; Figure $5 \mathrm{~h}$ ) in the subthreshold stress groups but not in the non-stressed groups.

Overall, these results indicate that EphB2 knockdown in the mPFC but not in the OFC increased the susceptibility to stress, which was associated with decreases in the phosphorylation levels of cofilin and the expression of some synaptic proteins.

\section{EphB2 Regulates Stress-Induced Dendritic Spine Remodeling in the mPFC}

Previous studies showed that chronic stress decreased the density and function of spine synapses in the mPFC (Li et al, 2010; Radley et al, 2005; Radley et al, 2006). EphB2 has been reported to control the stability of mature dendritic spines partially by suppressing cofilin activity (Shi et al, 2009). We investigated the effects of modulating EphB2 signaling in the mPFC on the stress-induced decrease in spine density. Two groups of mice (susceptible group and non-stressed group) were microinjected with EphrinB1/Fc or $\mathrm{Fc}$ in the mPFC. One hour later, the mice were perfused, and brain tissues were collected for Golgi-Cox staining (Figure 7a). We found that chronic social defeat stress significantly decreased total spine density in the mPFC in susceptible mice, and EphrinB1/Fc microinfusion in the mPFC in susceptible mice reversed the decrease in total spine density (two-way ANOVA, stress $\times$ drug interaction, $\mathrm{F}_{1,116}=4.018, \quad p<0.05 ;$ Figure $7 \mathrm{~b}$ and Supplementary Figure S7B).

Next we assessed the effects of EphB2 knockdown on the spine density of mPFC neurons using a subthreshold chronic social defeat stress model. Mice received a microinfusion of $A d V_{\text {shEphB2 }}$ or $A d V_{\text {Scramble }}$ in the $\mathrm{mPFC}$ and were subjected to 3 days of subthreshold stress. One hour later, they were killed, and brain tissues were collected for Golgi-Cox staining (Figure 7c). EphB2 knockdown in the mPFC decreased total spine density (two-way ANOVA, stress $\times$ vector interaction, $\mathrm{F}_{1,116}=3.953, p<0.05$; Figure $7 \mathrm{~d}$ and Supplementary Figure S7D) after subthreshold social defeat

Figure 3 Activation of EphB2 in the mPFC produced long-term antidepressant-like effects. (a) Experimental timeline of chronic social defeat stress and EphrinBI/Fc microinjection in the MPFC 10 days before the behavioral tests. (b) Social interaction ratio and time spent in the interaction zone in the social interaction (SI) test. (c) Sucrose preference in the sucrose preference test (SPT). (d) Latency to feed over 5 min in the novelty-suppressed feeding test (NSFT). (e) Number of crossings during the 5 min open field test 10 days after EphrinBl/Fc microinjection in the mPFC ( $n=10-12$ per group). ( $f$ ) EphB2 downstream proteins levels in the MPFC and representative western blottings 10 days after the microinjection $(n=9-11$ per group). The EphB2 downstream proteins included phosphorylated cofilin, cofilin, PSD95, synapsin I, and membranous GluRI and GluR2. *p<0.05, compared with the non-stressed Fc group; $\# p<0.05$, compared with the susceptible Fc group. 
stress. Neither subthreshold social defeat stress nor EphB2 knockdown in non-stressed mice affected total spine density (Figure 7d). Altogether, these results indicate that the decrease in spine density in the mPFC was associated with susceptibility to stress, and EphB2 downregulation in the mPFC increased the vulnerability to stress. a

Timeline

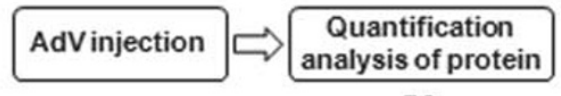

D1

D8
C

Expression levels of EphB2 protein

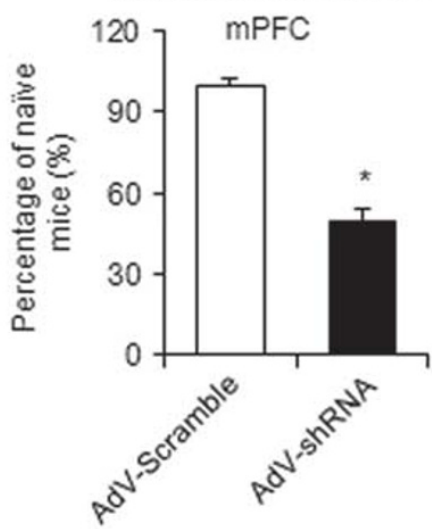

EphB2

GAPDH
Timeline

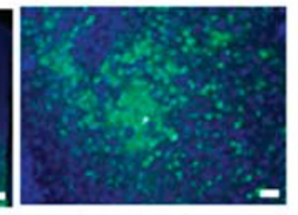

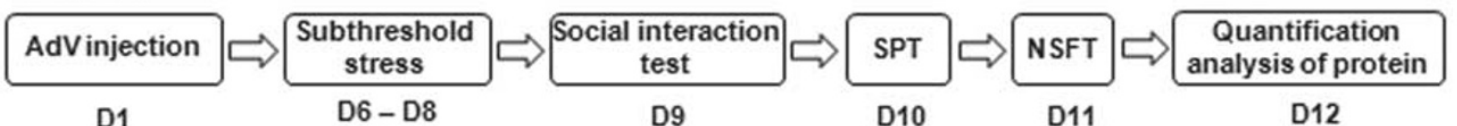

Social interaction test

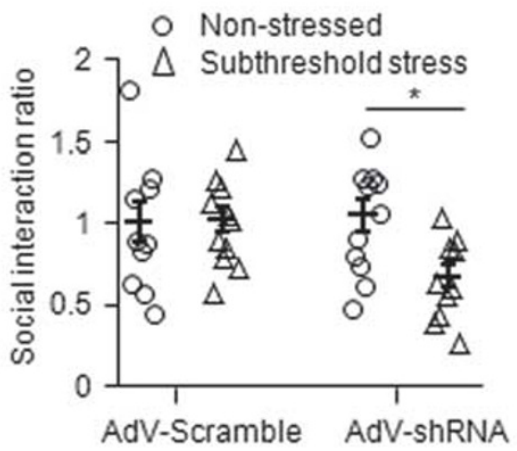

f

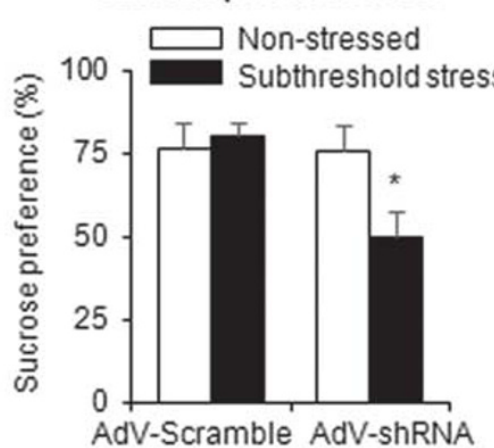

g Novelty suppressed
feeding test

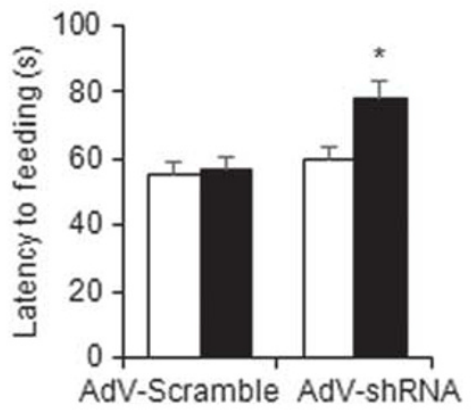

h

Protein levels in mPFC
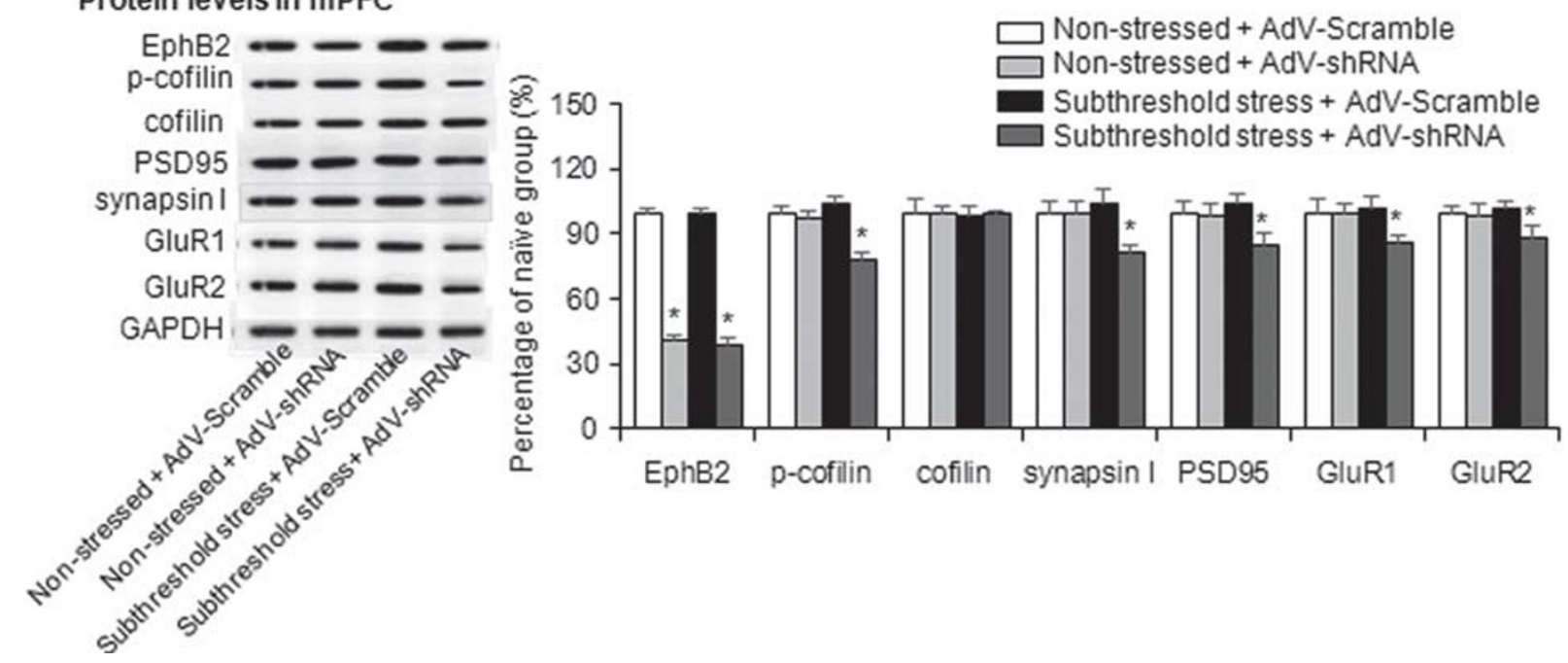

Neuropsychopharmacology 


\section{DISCUSSION}

In the present study, we found that chronic social defeat stress decreased the expression of EphB2 and downstream proteins in the $\mathrm{mPFC}$ in susceptible mice but not in resilient mice. EphB2 activation in the mPFC promoted resilience to stress, and this effect persisted for at least 10 days, whereas EphB2 knockdown induced depressive-like behaviors in the subthreshold social defeat stress paradigm. These behavioral effects were associated with changes in the phosphorylation of cofilin and the expression of some synaptic proteins in the mPFC. Moreover, we found that EphB2 activation reversed the decrease in spine density in the mPFC in susceptible mice that was induced by chronic social defeat stress. EphB2 knockdown decreased the spine density of mPFC neurons in the subthreshold social defeat stress paradigm, which is not normally sufficient to decrease spine density. Altogether, our results indicate that EphB2 signaling in the $\mathrm{mPFC}$ is critical for regulating structural plasticity and the vulnerability to stress, and we propose a model that depicts the possible signaling cascade of EphB2 that regulates stress vulnerability (Figure 8).

The mPFC is sensitive to the detrimental effects of stress, and its dysfunction has been implicated in the pathophysiology a

Representative pictures
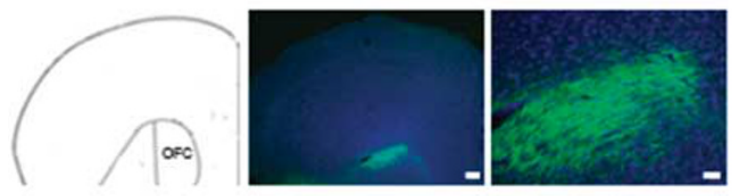

b

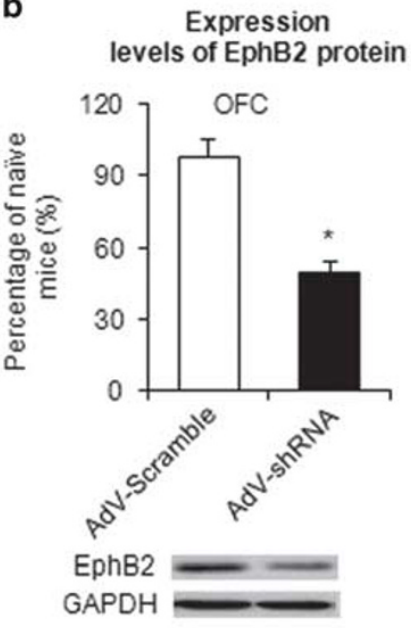

c

Social interaction test - OFC

- Non-stressed

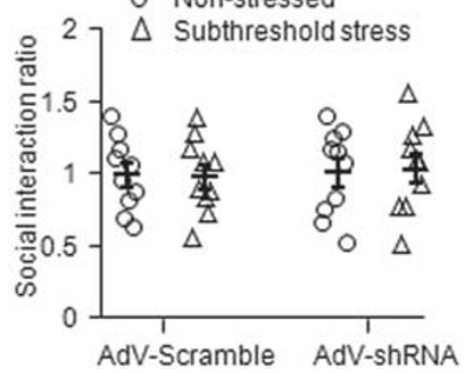

d Sucrose preference test - OFC

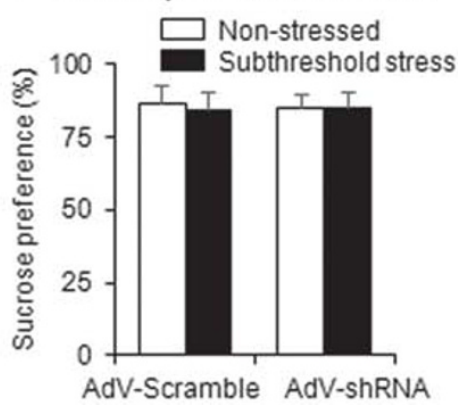

e
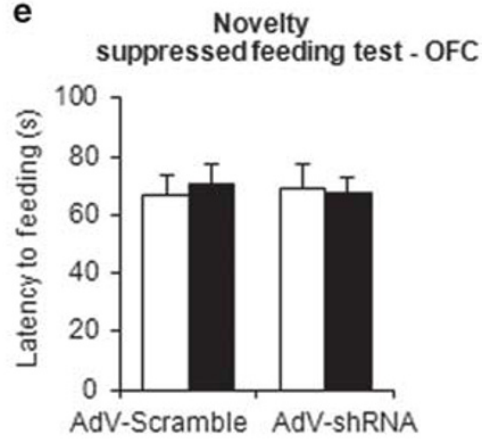

Figure 6 Knockdown of EphB2 in the OFC had no impact on the behavioral effects of subthreshold chronic social defeat stress. (a) Representative photographs of the injection sites and coronal brain sections in the OFC. The figure shows representative micrographs of adenovirus vector-mediated enhanced green fluorescent protein (eGFP; green), counterstained with DAPI, after OFC microinjection. Scale bars $=200 \mu \mathrm{m}$ (low-power images) and $50 \mu \mathrm{m}$

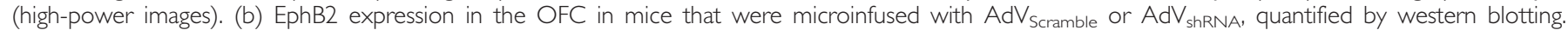

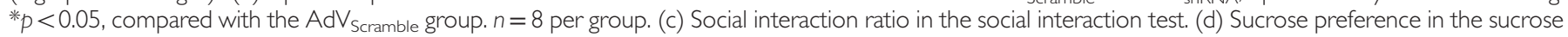
preference test. (e) Latency to feed over $5 \mathrm{~min}$ in the novelty-suppressed feeding test after intra-OFC microinjection of $A d V_{\text {scramble }}$ or $A d V_{\text {shRNA }}(n=9$ - I0 per group).

Figure 5 Knockdown of EphB2 in the mPFC induced depressive-like behaviors in the subthreshold chronic social defeat stress paradigm. (a) Experimental timeline for EphB2 detection. (b) Representative photographs of the injection sites and coronal brain sections in the mPFC. The figure shows representative micrographs of adenovirus vector-mediated enhanced green fluorescent protein (eGFP; green), counterstained with DAPI, after mPFC microinjection. Scale bars $=200 \mu \mathrm{m}$ (low-power images) and $50 \mu \mathrm{m}$ (high-power images). (c) EphB2 expression in the mPFC in mice that were microinfused with AdV $\mathrm{Scramble}_{\text {or }}$

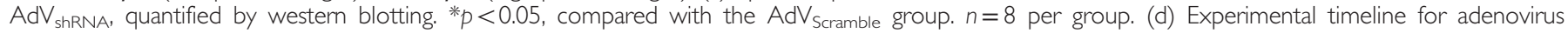
microinjection and subthreshold chronic social defeat stress. (e) Social interaction ratio in the social interaction test. (f) Sucrose preference in the sucrose preference test (SPT). (g) Latency to feed over $5 \mathrm{~min}$ in the novelty-suppressed feeding test (NSFT) after intra-mPFC microinjection of AdV $\mathrm{Scramble}_{\text {or }}$ $\operatorname{AdV}_{\text {shRNA }}(n=10-1 \mid$ per group). (h) EphB2 and downstream protein levels in the mPFC and representative western blottings ( $n=10-1 \mid$ per group). The EphB2 downstream proteins included phosphorylated cofilin, cofilin, PSD95, synapsin I, and membranous GluRI and GluR2. *p<0.05, compared with subthreshold stress $A d V_{\text {Scramble group. }}$ 
a

Timeline

\begin{tabular}{|c|c|c|c|c|}
\hline $\begin{array}{l}\text { Chronic social } \\
\text { defeat stress }\end{array}$ & $\Rightarrow \begin{array}{c}\text { Social interaction } \\
\text { test }\end{array}$ & $\begin{array}{l}\text { EphrinB1/Fc or } \\
\text { PBS/Fc injection }\end{array}$ & $\Leftrightarrow$ & Perfusion \\
\hline
\end{tabular}

b

Spine numbers

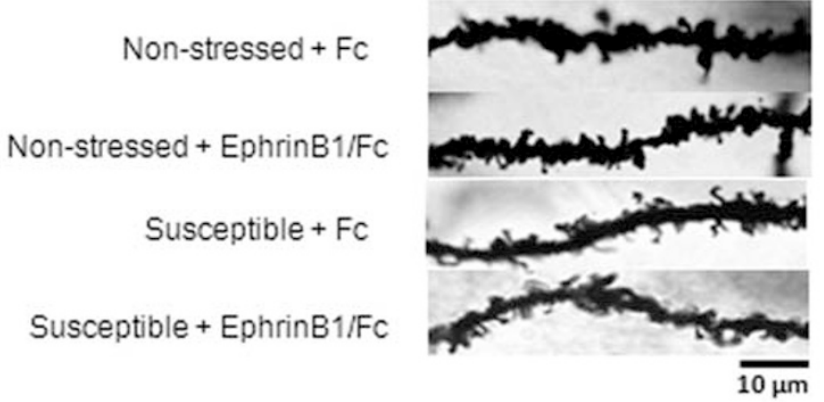

Timeline
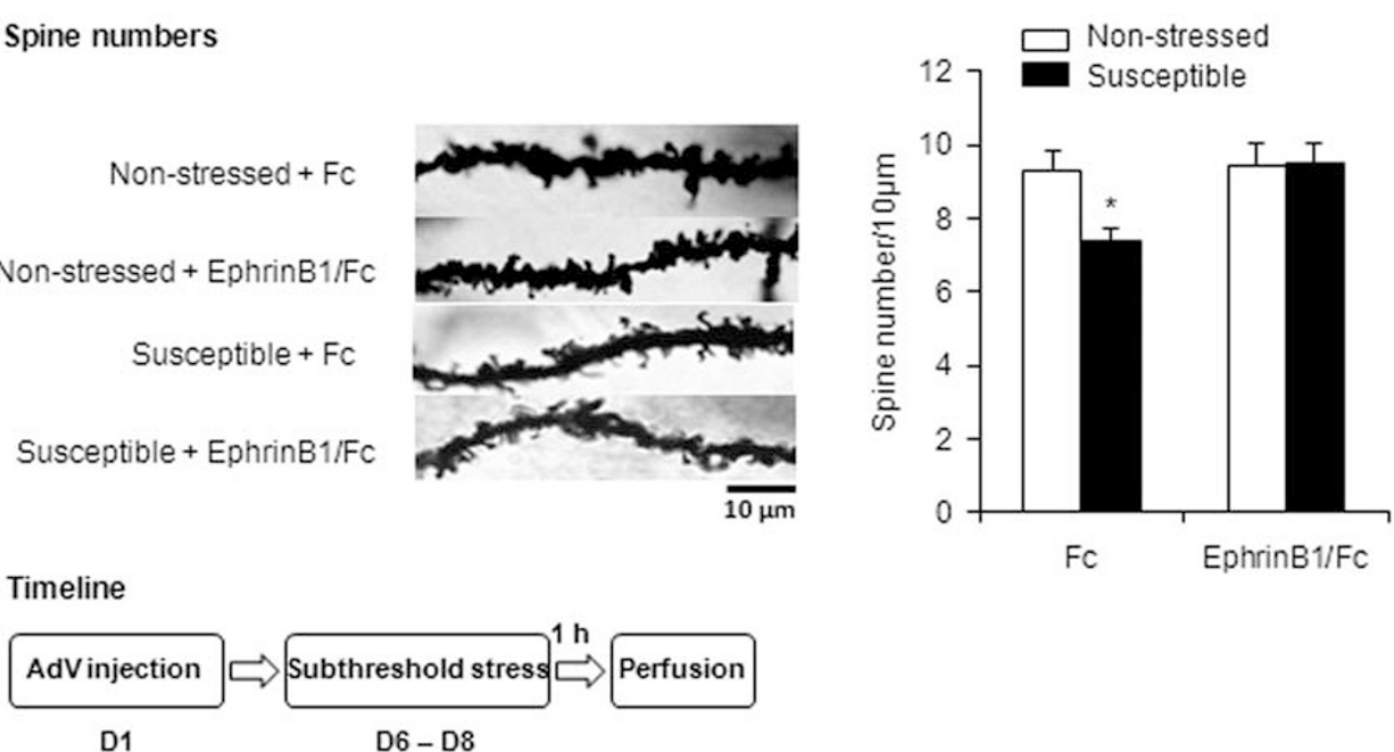

D1

D6 - D8

d

Spine numbers
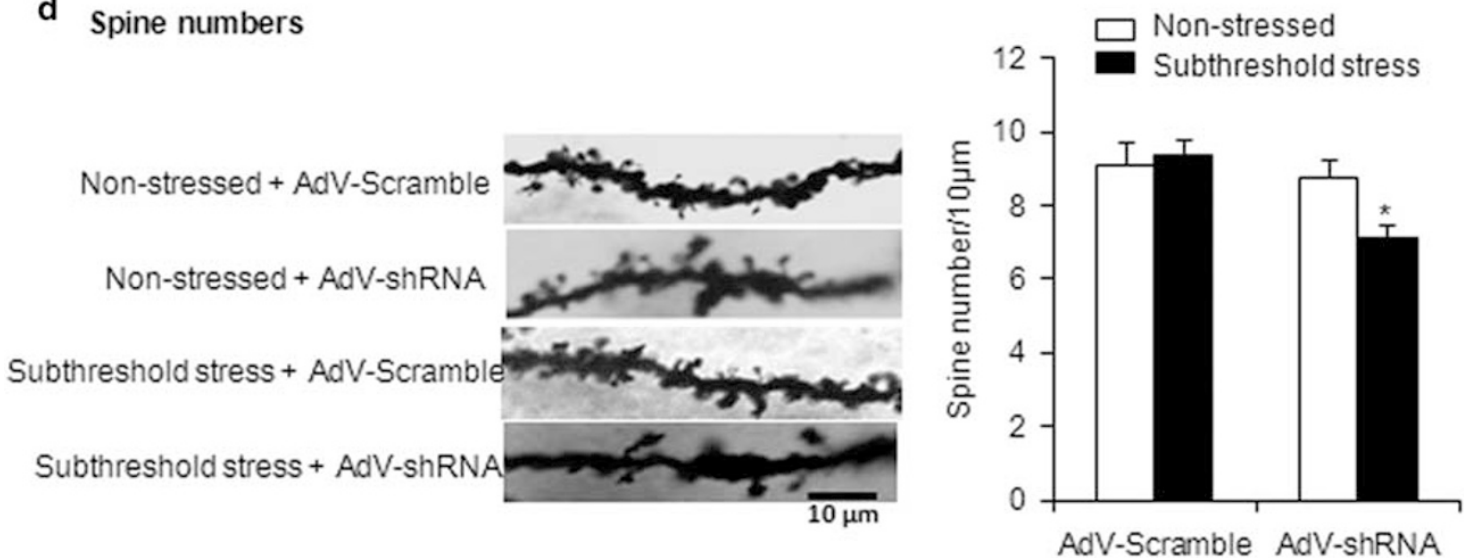

Figure 7 EphB2 influenced the number of dendritic spines in the mPFC. (a) Experimental timeline of chronic social defeat stress and EphrinBI/Fc microinjection. (b) Representative photograph of Golgi-Cox staining and total dendritic spine density under different conditions. $* p<0.05$, compared with the non-stressed Fc group. $n=3-5$ per group. Thirty neurons per group were analyzed and three dendritic segments of each neuron were selected for the analysis. (c) Experimental timeline of adenovirus microinjection and subthreshold chronic social defeat stress. (d) Representative photograph of Golgi-Cox staining and total dendritic spine density under different conditions. ${ }^{*} p<0.05$, compared with the subthreshold stress $A d V_{S c r a m b l e}$ group. $n=3-5$ per group. Thirty neurons were analyzed per group, and three dendritic segments of each neuron were selected for the analysis.

of stress-related disorders (Arnsten, 2009). Previous studies showed that the optogenetic activation of $\mathrm{mPFC}$ in susceptible mice reversed depressive-like behavior after chronic social defeat stress (Covington et al, 2010; Vialou et al, 2014). The application of $N$-methyl-D-aspartate (NMDA) receptor antagonists produced antidepressant-like effects by increasing synaptic plasticity and glutamatergic transmission in the mPFC (Miller et al, 2014; Zhang et al, 2015; Zhu et al, 2013). The OFC is adjacent to the mPFC. The role of the OFC in the stress response is controversial. Previous studies showed that spine density in the OFC was increased after 21 days of repeated restraint stress (Liston et al, 2006), whereas stress during development caused a loss of spines in the OFC (Muhammad et al, 2012). In the present study, we found that chronic social defeat stress decreased the expression of EphB2 and downstream proteins in the $\mathrm{mPFC}$ but not in the OFC in susceptible mice. Furthermore, the modulation of EphB2 signaling in the $\mathrm{mPFC}$ but not in the OFC regulated the vulnerability to stress. These results indicate that the effects of EphB2 on stress vulnerability were anatomically specific.

The tyrosine kinase receptor EphB2 has an important role in regulating neuronal development and maturation, GluR function, and synaptic plasticity. EphB2 is enriched at 


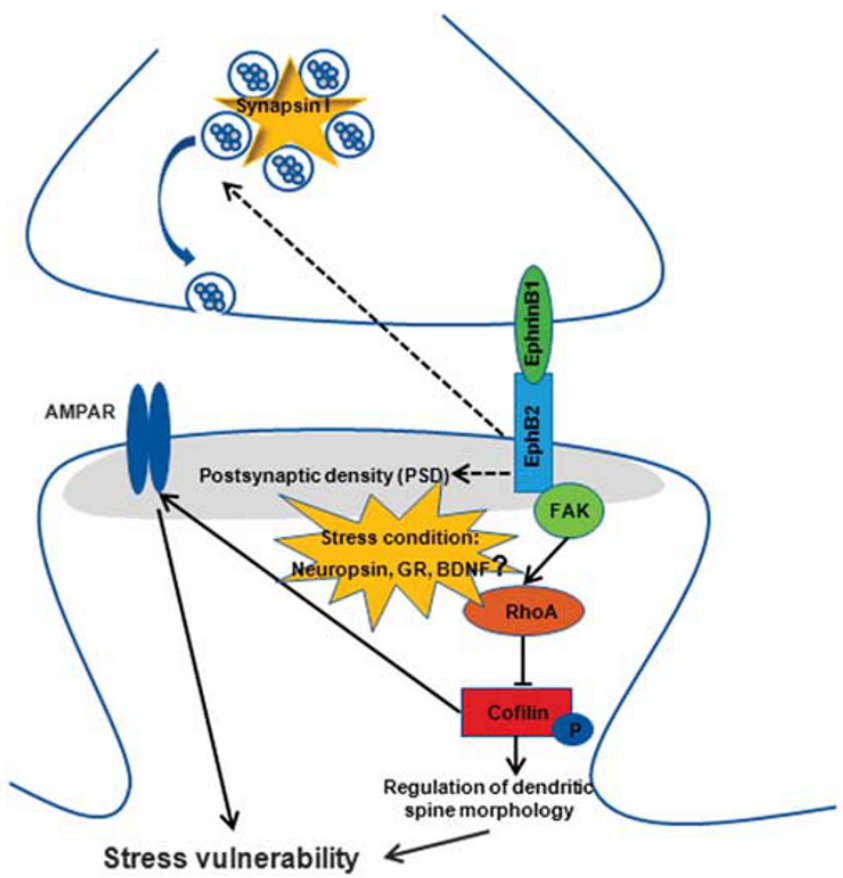

Figure 8 Proposed model of the possible signaling cascade of EphB2 that regulates stress vulnerability. EphB2 has been previously shown to inactivate cofilin through the FAK-dependent activation of RhoA, which maintains the morphology of mature spines. Chronic social defeat stress decreased the expression of EphB2 and some synaptic proteins and the phosphorylation of cofilin in the mPFC in susceptible mice. EphB2 may regulate stress vulnerability by modulating spine remodeling and synaptic plasticity via cofilin and AMPA receptor trafficking in the mPFC. Under subthreshold stress conditions, other stress-sensitive molecules, such as neuropsin, glucocorticoid receptors (GRs), brain-derived neurotrophic factor (BDNF), and corticotropin-releasing factor receptors, may interact with EphB2 to regulate spine structure and ultimately depressive-like behavior.

excitatory synapses in the mature brain and is involved in synapse and spine formation and maintenance (Aoto and Chen, 2007). EphB2-deficient mice exhibited impairments in synaptic transmission and plasticity (Simon et al, 2009) and a decrease in the mobility of postsynaptic dendritic filopodia during synapse formation in vitro (Kayser et al, 2008). EphB2 also has an important role in dendritic spine morphogenesis in hippocampal neurons, which may be mediated by the clustering of endogenous syndecan- 2 or actin polymerization through Rho-family guanosine triphosphatases (Ethell et al, 2001; Irie and Yamaguchi, 2002; Shi et al, 2009). Previous studies showed that the improper expression of EphB2 contributes to central nervous system diseases. A reduction of hippocampal EphB2 was associated with impaired cognitive function in a mouse model of Alzheimer's disease (Cisse et al, 2011; Simon et al, 2009), whereas EphB2 blockade in the amygdala hindered the development of restraint stress-induced anxiety (Attwood et al, 2011). EphB2 also has a role in emotional learning and memory (Cruz et al, 2015; Dines et al, 2015; Trabalza et al, 2012). In the present study, we found that EphB2 activation in the $\mathrm{mPFC}$ promoted resilience to stress, whereas EphB2 knockdown in the mPFC induced depressive-like behaviors in the subthreshold social defeat stress paradigm. Our results demonstrate that manipulating EphB2 signaling alters the vulnerability to stress.
Cofilin is a crucial regulator of actin dynamics and has important roles in dendritic spine remodeling, synaptic plasticity, and ultimately behavior (Rust, 2015). Cofilin has been implicated in the pathogenesis of neurodegenerative diseases (Garvalov et al, 2007; Minamide et al, 2000), the formation and maintenance of memories (Kramar et al, 2013; Wang et al, 2013), and stress-induced spine loss (Castaneda et al, 2015). Cofilin activity is regulated by phosphorylation. Previous studies showed that EphB2 activation suppressed cofilin activity by LIMK-mediated phosphorylation (Shi et al, 2009), which is consistent with our findings, in which EphB2 activation with EphrinB1-Fc reversed the decrease in $\mathrm{p}$-cofilin that was induced by chronic social defeat stress. Cofilin inactivation has been reported to increase the number of mature spines with large heads (Rust et al, 2010; Shi et al, 2009) and protect neurons against amyloid $\beta$-induced spine loss (Davis et al, 2011; Shankar et al, 2007). In the present study, we found that EphB2 activation increased the total spine density in the mPFC in susceptible mice, which may be mediated by cofilin phosphorylation. Once dephosphorylated, activated cofilin can conjunct with actin fibers and induce depolymerization of the cytoskeleton, which induces the shrinkage of dendritic spines (Tomasella et al, 2014). Cofilin activation by dephosphorylation leads to the destabilization and transformation of mature mushroom spines into immature thin spines in hippocampal neurons (Shi and Ethell, 2006; Shi et al, 2009). Therefore, EphB2 knockdown decreased the total spine density likely through cofilin dephosphorylation. Alterations in the density and organization of spines in the mPFC are thought to contribute to the behavioral symptoms of depression (Duman and Duman, 2015). Altogether, this signaling cascade connects extracellular stimuli with dynamic reorganization of the actin cytoskeleton, which ultimately contributes to spine remodeling and depressionrelated behavior.

Previous studies showed that EphB2 controls the surface trafficking of GluR1 and GluR2 in neurons and has been implicated in cognitive disorders (Hussain et al, 2015; Miyamoto et al, 2016). We also found that EphB2 modulation in the mPFC influenced the expression of membrane GluR1 and GluR2. Moreover, cofilin was shown to regulate AMPA receptor trafficking and synaptic plasticity (Gu et al, 2010; Mizuno, 2013; Shen et al, 2009). Increases in p-cofilin levels are accompanied by additional AMPA receptor trafficking during long-term potentiation (Wang et al, 2013), whereas active ADF (actin depolymerizing factor)/cofilin is needed for spine pruning during long-term depression (Zhou et al, 2004). The synaptic insertion or removal of AMPA receptors regulates synaptic strength and participates in behavioral modification (Kessels and Malinow, 2009). The enhancement of AMPA receptor function produces antidepressant-like effects (Alt et al, 2005; Andreasen et al, 2015; Farley et al, 2010) and mediates the response to antidepressant treatment (Zhang et al, 2013). AMPAR regulation is also linked to individual variations in stress vulnerability (Schmidt et al, 2010; Vialou et al, 2010). In the present study, we found that chronic social defeat stress significantly reduced total spine density in the mPFC in susceptible mice, accompanied by a decrease in the expression of GluR1 and GluR2, suggesting that glutamatergic synaptic transmission was impaired in the $\mathrm{mPFC}$ in 
susceptible mice, which is consistent with previous studies (Vialou et al, 2014; Yuen et al, 2012). Altogether, we speculate that EphB2 influences stress vulnerability by modulating spine remodeling and synaptic plasticity via cofilin and AMPA receptor trafficking in the mPFC.

However, conclusions that are drawn with regard to the causal role of EphB2 in the regulation of cofilin phosphorylation and AMPA receptor trafficking during social defeat stress should be made with caution. EphB2 knockdown reduced the phosphorylation of cofilin and the expression of membrane GluR1 and GluR2 only under the condition of subthreshold stress, indicating that additional signaling mechanisms that are engaged by subthreshold stress appear to converge with EphB2 to drive the changes in downstream signals and behavioral outcomes. Indeed, restraint stress induced the neuropsin-dependent cleavage of EphB2 in the amygdala and triggered its dissociation from NR1, resulting in modulation of the expression of NMDA receptordependent genes (Attwood et al, 2011). Additionally, under conditions of stress, glucocorticoid receptors (GRs) may translocate to the nucleus and promote local gene transcription. Alternatively, GRs may translocate to synapses and promote the LIMK1-dependent phosphorylation of cofilin (van der Kooij et al, 2016). Chronic stressor exposure can desensitize GRs, diminish their transcriptional activity, and produce detrimental effects (Sousa et al, 2008). Stressregulated cofilin was also found to depend on RAC-1 signaling (Golden et al, 2013). Other stress-sensitive molecules, such as brain-derived neurotrophic factor and corticotropin-releasing factor receptors, may interact with EphB2 to regulate spine structure and ultimately depressivelike behavior.

We also evaluated the effects of stress and EphB2 on the levels of other synaptic proteins, including synapsin I and PSD95, in the mPFC. We found that EphrinB1/Fc reversed the decreases in synapsin I and PSD95 that were induced by chronic social defeat stress, whereas EphB2 knockdown decreased the levels of synapsin I and PSD95 in the subthreshold defeat stress paradigm, suggesting that EphB2 may regulate structural and synaptic plasticity in both a presynaptic and postsynaptic manner.

In conclusion, our results indicate that EphB2 activation in the $\mathrm{mPFC}$ produces rapid and prolonged stress-resistant and antidepressant-like effects by regulating spine density. These findings provide further insights into the molecular mechanisms that underlie stress resilience. Targeting EphB2 signaling may be considered a practical therapeutic strategy for depression.

\section{FUNDING AND DISCLOSURE}

This work was supported in part by the National Basic Research Program of China (nos. 2015CB856400 and 2015CB553503) and National Natural Science Foundation of China (nos. 31230033, 91432303, and 81221002). The authors declare no conflict of interest.

\section{ACKNOWLEDGMENTS}

Dr Yavin Shaham provided helpful suggestions for preparing the article.

\section{Author contributions}

$\mathrm{RZ}, \mathrm{YH}, \mathrm{WZ}$, and LL conceived the project and designed the experiments. RZ, LX, JL, NC, and CS performed the experiments. RZ, YH, and $\mathrm{WZ}$ analyzed the data. RZ, CC, $\mathrm{YH}$, and LL wrote the paper with contributions from all of the other authors.

\section{REFERENCES}

Alt A, Witkin JM, Bleakman D (2005). AMPA receptor potentiators as novel antidepressants. Curr Pharm Des 11: 1511-1527.

Andreasen JT, Fitzpatrick CM, Larsen M, Skovgaard L, Nielsen SD, Clausen RP et al (2015). Differential role of AMPA receptors in mouse tests of antidepressant and anxiolytic action. Brain Res 1601: 117-126.

Aoto J, Chen L (2007). Bidirectional ephrin/Eph signaling in synaptic functions. Brain Res 1184: 72-80.

Arnsten AF (2009). Stress signalling pathways that impair prefrontal cortex structure and function. Nat Rev Neurosci 10: $410-422$.

Attwood BK, Bourgognon JM, Patel S, Mucha M, Schiavon E, Skrzypiec AE et al (2011). Neuropsin cleaves EphB2 in the amygdala to control anxiety. Nature 473: 372-375.

Bloss EB, Janssen WG, Ohm DT, Yuk FJ, Wadsworth S, Saardi KM et al (2011). Evidence for reduced experience-dependent dendritic spine plasticity in the aging prefrontal cortex. J Neurosci 31: 7831-7839.

Bouvier D, Corera AT, Tremblay ME, Riad M, Chagnon M, Murai KK et al (2008). Pre-synaptic and post-synaptic localization of EphA4 and EphB2 in adult mouse forebrain. J Neurochem 106: 682-695.

Brambilla R, Klein R (1995). Telling axons where to grow: a role for Eph receptor tyrosine kinases in guidance. Mol Cell Neurosci 6: 487-495.

Castaneda P, Munoz M, Garcia-Rojo G, Ulloa JL, Bravo JA, Marquez R et al (2015). Association of N-cadherin levels and downstream effectors of Rho GTPases with dendritic spine loss induced by chronic stress in rat hippocampal neurons. J Neurosci Res 93: 1476-1491.

Chai N, Liu JF, Xue YX, Yang C, Yan W, Wang HM et al (2014). Delayed noradrenergic activation in the dorsal hippocampus promotes the long-term persistence of extinguished fear. Neuropsychopharmacology 39: 1933-1945.

Cisse M, Halabisky B, Harris J, Devidze N, Dubal DB, Sun B et al (2011). Reversing EphB2 depletion rescues cognitive functions in Alzheimer model. Nature 469: 47-52.

Covington HE 3rd, Lobo MK, Maze I, Vialou V, Hyman JM, Zaman S et al (2010). Antidepressant effect of optogenetic stimulation of the medial prefrontal cortex. J Neurosci 30: 16082-16090.

Covington HE 3rd, Maze I, LaPlant QC, Vialou VF, Ohnishi YN, Berton $\mathrm{O}$ et al (2009). Antidepressant actions of histone deacetylase inhibitors. J Neurosci 29: 11451-11460.

Covington HE 3rd, Maze I, Sun H, Bomze HM, DeMaio KD, $\mathrm{Wu} \mathrm{EY}$ et al (2011). A role for repressive histone methylation in cocaine-induced vulnerability to stress. Neuron 71: 656-670.

Cruz E, Soler-Cedeno O, Negron G, Criado-Marrero M, Chompre G, Porter JT (2015). Infralimbic EphB2 modulates fear extinction in adolescent rats. J Neurosci 35: 12394-12403.

Davis RC, Marsden IT, Maloney MT, Minamide LS, Podlisny M, Selkoe DJ et al (2011). Amyloid beta dimers/trimers potently induce cofilin-actin rods that are inhibited by maintaining cofilinphosphorylation. Mol Neurodegener 6: 10.

Dines M, Grinberg S, Vassiliev M, Ram A, Tamir T, Lamprecht R (2015). The roles of Eph receptors in contextual fear conditioning memory formation. Neurobiol Learn Mem 124: 62-70. 
Drevets WC, Price JL, Simpson JR Jr, Todd RD, Reich T, Vannier M et al (1997). Subgenual prefrontal cortex abnormalities in mood disorders. Nature 386: 824-827.

Duman CH, Duman RS (2015). Spine synapse remodeling in the pathophysiology and treatment of depression. Neurosci Lett 601: $20-29$.

Ethell IM, Irie F, Kalo MS, Couchman JR, Pasquale EB, Yamaguchi Y (2001). EphB/syndecan-2 signaling in dendritic spine morphogenesis. Neuron 31: 1001-1013.

Faccidomo S, Bannai M, Miczek KA (2008). Escalated aggression after alcohol drinking in male mice: dorsal raphe and prefrontal cortex serotonin and $5-\mathrm{HT}_{1 \mathrm{~B}}$ receptors. Neuropsychopharmacology 33: 2888-2899.

Farley S, Apazoglou K, Witkin JM, Giros B, Tzavara ET (2010). Antidepressant-like effects of an AMPA receptor potentiator under a chronic mild stress paradigm. Int J Neuropsychopharmacol 13: $1207-1218$.

Garvalov BK, Flynn KC, Neukirchen D, Meyn L, Teusch N, Wu X et al (2007). Cdc42 regulates cofilin during the establishment of neuronal polarity. J Neurosci 27: 13117-13129.

Golden SA, Christoffel DJ, Heshmati M, Hodes GE, Magida J, Davis $\mathrm{K}$ et al (2013). Epigenetic regulation of RAC1 induces synaptic remodeling in stress disorders and depression. Nat Med 19: $337-344$.

Golden SA, Covington HE 3rd, Berton O, Russo SJ (2011). A standardized protocol for repeated social defeat stress in mice. Nat Protoc 6: 1183-1191.

Gu J, Lee CW, Fan Y, Komlos D, Tang X, Sun C et al (2010). $\mathrm{ADF} /$ cofilin-mediated actin dynamics regulate AMPA receptor trafficking during synaptic plasticity. Nat Neurosci 13: 1208-1215.

Han Y, Luo Y, Sun J, Ding Z, Liu J, Yan W et al (2015). AMPK signaling in the dorsal hippocampus negatively regulates contextual fear memory formation. Neuropsychopharmacology doi:10.1038/npp.2015.355 (epub ahead of print).

Himanen JP, Nikolov DB (2003). Eph receptors and ephrins. Int J Biochem Cell Biol 35: 130-134.

Hussain NK, Thomas GM, Luo J, Huganir RL (2015). Regulation of AMPA receptor subunit GluA1 surface expression by PAK3 phosphorylation. Proc Natl Acad Sci USA 112: E5883-E5890.

Irie F, Yamaguchi Y (2002). EphB receptors regulate dendritic spine development via intersectin, Cdc42 and N-WASP. Nat Neurosci 5: 1117-1118.

Jian M, Luo YX, Xue YX, Han Y, Shi HS, Liu JF et al (2014). eIF2 $\alpha$ dephosphorylation in basolateral amygdala mediates reconsolidation of drug memory. J Neurosci 34: 10010-10021.

Kayser MS, McClelland AC, Hughes EG, Dalva MB (2006). Intracellular and trans-synaptic regulation of glutamatergic synaptogenesis by EphB receptors. J Neurosci 26: 12152-12164.

Kayser MS, Nolt MJ, Dalva MB (2008). EphB receptors couple dendritic filopodia motility to synapse formation. Neuron 59: 56-69.

Kendler KS, Karkowski LM, Prescott CA (1999). Causal relationship between stressful life events and the onset of major depression. Am J Psychiatry 156: 837-841.

Kessels HW, Malinow R (2009). Synaptic AMPA receptor plasticity and behavior. Neuron 61: 340-350.

Klein R (2004). Eph/ephrin signaling in morphogenesis, neural development and plasticity. Curr Opin Cell Biol 16: 580-589.

Kramar EA, Babayan AH, Gall CM, Lynch G (2013). Estrogen promotes learning-related plasticity by modifying the synaptic cytoskeleton. Neuroscience 239: 3-16.

Krishnan V, Han MH, Graham DL, Berton O, Renthal W, Russo SJ et al (2007). Molecular adaptations underlying susceptibility and resistance to social defeat in brain reward regions. Cell 131: 391-404.

Krishnan V, Nestler EJ (2008). The molecular neurobiology of depression. Nature 455: 894-902.
Li N, Lee B, Liu RJ, Banasr M, Dwyer JM, Iwata M et al (2010). mTOR-dependent synapse formation underlies the rapid antidepressant effects of NMDA antagonists. Science 329: 959-964.

Liston C, Miller MM, Goldwater DS, Radley JJ, Rocher AB, Hof PR et al (2006). Stress-induced alterations in prefrontal cortical dendritic morphology predict selective impairments in perceptual attentional set-shifting. J Neurosci 26: 7870-7874.

Lu L, Hope BT, Dempsey J, Liu SY, Bossert JM, Shaham Y (2005). Central amygdala ERK signaling pathway is critical to incubation of cocaine craving. Nat Neurosci 8: 212-219.

Luo YX, Xue YX, Liu JF, Shi HS, Jian M, Han Y et al (2015). A novel UCS memory retrieval-extinction procedure to inhibit relapse to drug seeking. Nat Commun 6: 7675.

Miller OH, Yang L, Wang CC, Hargroder EA, Zhang Y, Delpire E et al (2014). GluN2B-containing NMDA receptors regulate depression-like behavior and are critical for the rapid antidepressant actions of ketamine. Elife 3: e03581.

Minamide LS, Striegl AM, Boyle JA, Meberg PJ, Bamburg JR (2000). Neurodegenerative stimuli induce persistent $\mathrm{ADF} /$ cofilin-actin rods that disrupt distal neurite function. Nat Cell Biol 2: 628-636.

Miyamoto T, Kim D, Knox JA, Johnson E, Mucke L (2016). Increasing the receptor tyrosine kinase EphB2 prevents amyloid $\beta$-induced depletion of cell-surface glutamate receptors by a mechanism that requires EphB2's PDZ-binding motif and neuronal activity. J Biol Chem 291: 1719-1734.

Mizuno K (2013). Signaling mechanisms and functional roles of cofilin phosphorylation and dephosphorylation. Cell Signal 25: 457-469.

Muhammad A, Carroll C, Kolb B (2012). Stress during development alters dendritic morphology in the nucleus accumbens and prefrontal cortex. Neuroscience 216: 103-109.

Radley JJ, Rocher AB, Janssen WG, Hof PR, McEwen BS, Morrison JH (2005). Reversibility of apical dendritic retraction in the rat medial prefrontal cortex following repeated stress. Exp Neurol 196: 199-203.

Radley JJ, Rocher AB, Miller M, Janssen WG, Liston C, Hof PR et al (2006). Repeated stress induces dendritic spine loss in the rat medial prefrontal cortex. Cereb Cortex 16: 313-320.

Rajkowska G, Miguel-Hidalgo JJ, Wei J, Dilley G, Pittman SD, Meltzer HY et al (1999). Morphometric evidence for neuronal and glial prefrontal cell pathology in major depression. Biol Psychiatry 45: 1085-1098.

Restivo L, Ferrari F, Passino E, Sgobio C, Bock J, Oostra BA et al (2005). Enriched environment promotes behavioral and morphological recovery in a mouse model for the fragile $\mathrm{X}$ syndrome. Proc Natl Acad Sci USA 102: 11557-11562.

Russo SJ, Murrough JW, Han MH, Charney DS, Nestler EJ (2012). Neurobiology of resilience. Nat Neurosci 15: 1475-1484.

Rust MB (2015). ADF/cofilin: a crucial regulator of synapse physiology and behavior. Cell Mol Life Sci 72: 3521-3529.

Rust MB, Gurniak CB, Renner M, Vara H, Morando L, Gorlich A et al (2010). Learning, AMPA receptor mobility and synaptic plasticity depend on n-cofilin-mediated actin dynamics. EMBO J 29: 1889-1902.

Schmidt MV, Trumbach D, Weber P, Wagner K, Scharf SH, Liebl C et al (2010). Individual stress vulnerability is predicted by shortterm memory and AMPA receptor subunit ratio in the hippocampus. J Neurosci 30: 16949-16958.

Shankar GM, Bloodgood BL, Townsend M, Walsh DM, Selkoe DJ, Sabatini BL (2007). Natural oligomers of the Alzheimer amyloid $\beta$ protein induce reversible synapse loss by modulating an NMDAtype glutamate receptor-dependent signaling pathway. J Neurosci 27: 2866-2875.

Shen HW, Toda S, Moussawi K, Bouknight A, Zahm DS, Kalivas PW (2009). Altered dendritic spine plasticity in cocainewithdrawn rats. J Neurosci 29: 2876-2884.

Shen Q, Lal R, Luellen BA, Earnheart JC, Andrews AM, Luscher B (2010). Y-Aminobutyric acid-type A receptor deficits cause 
hypothalamic-pituitary-adrenal axis hyperactivity and antidepressant drug sensitivity reminiscent of melancholic forms of depression. Biol Psychiatry 68: 512-520.

Shi HS, Zhu WL, Liu JF, Luo YX, Si JJ, Wang SJ et al (2012). PI3K/ Akt signaling pathway in the basolateral amygdala mediates the rapid antidepressant-like effects of trefoil factor 3. Neuropsychopharmacology 37: 2671-2683.

Shi Y, Ethell IM (2006). Integrins control dendritic spine plasticity in hippocampal neurons through NMDA receptor and $\mathrm{Ca}^{2+} /$ calmodulin-dependent protein kinase II-mediated actin reorganization. J Neurosci 26: 1813-1822.

Shi Y, Pontrello CG, DeFea KA, Reichardt LF, Ethell IM (2009). Focal adhesion kinase acts downstream of EphB receptors to maintain mature dendritic spines by regulating cofilin activity. J Neurosci 29: 8129-8142.

Simon AM, de Maturana RL, Ricobaraza A, Escribano L, Schiapparelli L, Cuadrado-Tejedor M et al (2009). Early changes in hippocampal Eph receptors precede the onset of memory decline in mouse models of Alzheimer's disease. J Alzheimers Dis 17: 773-786.

Sousa N, Cerqueira JJ, Almeida OF (2008). Corticosteroid receptors and neuroplasticity. Brain Res Rev 57: 561-570.

Suo L, Zhao L, Si J, Liu J, Zhu W, Chai B et al (2013). Predictable chronic mild stress in adolescence increases resilience in adulthood. Neuropsychopharmacology 38: 1387-1400.

Tomasella A, Blangy A, Brancolini C (2014). A receptor-interacting protein 1 (RIP1)-independent necrotic death under the control of protein phosphatase PP2A that involves the reorganization of actin cytoskeleton and the action of cofilin-1. J Biol Chem 289: 25699-25710.

Trabalza A, Colazingari S, Sgobio C, Bevilacqua A (2012). Contextual learning increases dendrite complexity and EphrinB2 levels in hippocampal mouse neurons. Behav Brain Res 227: 175-183.

van der Kooij MA, Masana M, Rust MB, Muller MB (2016). The stressed cytoskeleton: how actin dynamics can shape stressrelated consequences on synaptic plasticity and complex behavior. Neurosci Biobehav Rev 62: 69-75.

Vialou V, Bagot RC, Cahill ME, Ferguson D, Robison AJ, Dietz DM et al (2014). Prefrontal cortical circuit for depression- and anxiety-related behaviors mediated by cholecystokinin: role of $\Delta$ FosB. J Neurosci 34: 3878-3887.
Vialou V, Robison AJ, Laplant QC, Covington HE 3rd, Dietz DM, Ohnishi YN et al (2010). $\Delta$ FosB in brain reward circuits mediates resilience to stress and antidepressant responses. Nat Neurosci 13: 745-752.

Wang Y, Dong Q, Xu XF, Feng X, Xin J, Wang DD et al (2013). Phosphorylation of cofilin regulates extinction of conditioned aversive memory via AMPAR trafficking. J Neurosci 33: 6423-6433.

Xue YX, Luo YX, Wu P, Shi HS, Xue LF, Chen C et al (2012). A memory retrieval-extinction procedure to prevent drug craving and relapse. Science 336: 241-245.

Xue YX, Zhu ZZ, Han HB, Liu JF, Meng SQ, Chen C et al (2015). Overexpression of protein kinase $\mathrm{M} \zeta$ in the prelimbic cortex enhances the formation of long-term fear memory. Neuropsychopharmacology 40: 2146-2156.

Yang J, Luo X, Huang X, Ning Q, Xie M, Wang W (2014). EphrinA3 reverse signaling regulates hippocampal neuronal damage and astrocytic glutamate transport after transient global ischemia. J Neurochem 131: 383-394.

Yu H, Wang DD, Wang Y, Liu T, Lee FS, Chen ZY (2012). Variant brain-derived neurotrophic factor Val66Met polymorphism alters vulnerability to stress and response to antidepressants. J Neurosci 32: 4092-4101.

Yuen EY, Wei J, Liu W, Zhong P, Li X, Yan Z (2012). Repeated stress causes cognitive impairment by suppressing glutamate receptor expression and function in prefrontal cortex. Neuron 73: 962-977.

Zhang H, Etherington LA, Hafner AS, Belelli D, Coussen F, Delagrange $P$ et al (2013). Regulation of AMPA receptor surface trafficking and synaptic plasticity by a cognitive enhancer and antidepressant molecule. Mol Psychiatry 18: 471-484.

Zhang JC, Yao W, Dong C, Yang C, Ren Q, Ma M et al (2015). Comparison of ketamine, 7,8-dihydroxyflavone, and ANA-12 antidepressant effects in the social defeat stress model of depression. Psychopharmacology (Berl) 232: 4325-4335.

Zhou Q, Homma KJ, Poo MM (2004). Shrinkage of dendritic spines associated with long-term depression of hippocampal synapses. Neuron 44: 749-757.

Zhu WL, Wang SJ, Liu MM, Shi HS, Zhang RX, Liu JF et al (2013). Glycine site $N$-methyl-D-aspartate receptor antagonist 7-CTKA produces rapid antidepressant-like effects in male rats. J Psychiatry Neurosci 38: 306-316.

Supplementary Information accompanies the paper on the Neuropsychopharmacology website (http://www.nature.com/npp) 